\title{
Eficacia, efectividad
}

y seguridad de

la radioterapia

intraoperatoria en

carcinoma de mama.

\section{Informes de Evaluación de Tecnologías Sanitarias.}





\section{Eficacia, efectividad}

y seguridad de

la radioterapia

intraoperatoria en

carcinoma de mama.

\section{Informes de Evaluación de Tecnologías Sanitarias.}

INFORMES, ESTUDIOS E INVESTIGACIÓN 
Eficacia, efectividad y seguridad de la radioterapia intraoperatoria en carcinoma de mama / Juan Ignacio Martín Sánchez, Silvia Vázquez Fernández del Pozo - Madrid: Ministerio de Sanidad, Consumo y Bienestar Social; Zaragoza:

Instituto Aragonés de Ciencias de la Salud (IACS), 201992 p. ; 24 cm. - (Informes, estudios e investigación) (Informes de evaluación de tecnologías sanitarias. IACS)

NIPO: 731-19-055-7.

ISBN: 978-84-09-13792-3.

1. Radioterapia intraoperatoria 2. Cáncer de mama

I. Martín Sánchez, Juan Ignacio II. España. Ministerio de Sanidad, Consumo y Bienestar Social III. Aragón. Instituto Aragonés de Ciencias de la Salud (IACS)

Edición: 2019

Edita: Ministerio de Sanidad, Consumo y Bienestar Social Instituto Aragonés de Ciencias de la Salud (IACS)

NIPO: 731-19-055-7

ISBN: 978-84-09-13792-3

Maquetación: ARPIrelieve, S. A. 
Este informe se realiza por el Instituto Aragonés de Ciencias de la Salud, en el marco de la financiación del Ministerio de Sanidad, Consumo y Bienestar Social para el desarrollo de las actividades del Plan anual de trabajo de la Red Española de Agencias de Evaluación de Tecnologías Sanitarias y Prestaciones del SNS, aprobado en el Pleno del Consejo Interterritorial de 13 de abril de 2016 (conforme al Acuerdo del Consejo de Ministros de 17 de junio de 2016).

Todas las personas que participan en la elaboración del informe, han cumplimentado la declaración de interés de la Red Española de Agencias de Evaluación de Tecnologías Sanitarias. Tras la aplicación del procedimiento de gestión de los conflictos de interés de la Red Española de Evaluación de Tecnologías Sanitarias y Prestaciones del SNS se declara que: ningún profesional fue excluido del proceso en base a la información declarada. Los revisores externos del documento no suscriben necesariamente todas y cada una de las conclusiones y recomendaciones finales, que son responsabilidad exclusiva de los autores.

Para citar este informe.

Martín Sánchez Jl, Vázquez Fernández del Pozo S. Eficacia, efectividad y seguridad de la radioterapia intraoperatoria en carcinoma de mama. Ministerio de Sanidad, Consumo y Bienestar Social. Instituto Aragonés de Ciencias de la Salud; 2019. Informes de Evaluación de Tecnologías Sanitarias: IACS. 



\section{Índice}

$\begin{array}{ll}\text { Autoría } & 9\end{array}$

$\begin{array}{ll}\text { Declaración de interés } & 10\end{array}$

$\begin{array}{ll}\text { Resumen } & 11\end{array}$

$\begin{array}{ll}\text { Summary } & 17\end{array}$

$\begin{array}{ll}\text { Abreviaturas } & 23\end{array}$

Glosario 25

$\begin{array}{ll}\text { Introducción y justificación } & 27\end{array}$

$\begin{array}{ll}\text { Objetivos } & 31\end{array}$

$\begin{array}{ll}\text { Metodología } & 33\end{array}$

$\begin{array}{ll}\text { Búsqueda bibliográfica } & 33\end{array}$

$\begin{array}{ll}\text { Criterios de selección de los estudios } & 34\end{array}$

$\begin{array}{ll}\text { Criterios de inclusión } & 34\end{array}$

Criterios de exclusión 34

Extracción de datos y evaluación de la calidad de los estudios 35

$\begin{array}{ll}\text { Resultados } & 37\end{array}$

$\begin{array}{ll}\text { Eficacia/efectividad de la RIO } & 38\end{array}$

$\begin{array}{ll}\text { Seguridad de la RIO } & 41\end{array}$

$\begin{array}{ll}\text { Preferencias de las mujeres } & 47\end{array}$

Preferencias de los profesionales de la salud $\quad 48$

$\begin{array}{ll}\text { Resultados estéticos } & 49\end{array}$

Calidad de vida percibida por las mujeres $\quad 52$

$\begin{array}{ll}\text { Seguridad del personal sanitario } & 53\end{array}$

Evaluación económica de la RIO 54 
Discusión

Conclusiones

Anexos

Anexo 1. Perfil de evidencia. RIO vs. EBRT

67

Anexo 2. Estudios incluidos

69

Anexo 3. Estudios excluidos

71

Anexo 4. Estrategias de búsqueda

75

Bibliografía

79 


\section{Autoría}

\section{Autores}

Juan Ignacio Martín Sánchez; Médico Especialista en Medicina Preventiva y Salud Pública. Instituto Aragonés de Ciencias de la Salud. Zaragoza.

Silvia Vázquez Fernández del Pozo. Médico Especialista en Medicina Preventiva y Salud Pública. Instituto Aragonés de Ciencias de la Salud. Zaragoza.

\section{Revisión externa:}

Manuela Lanzuela Valero. Especialista en Oncología Radioterápica. Hospital Universitario Miguel Servet. Zaragoza.

$\mathrm{M}^{\mathrm{a}}$ Carmen Velilla Millán. Especialista en Oncología Radioterápica. Hospital Clínico Universitario Lozano Blesa. Zaragoza.

\section{Documentalista}

María Pilar Blas Diez. Instituto Aragonés de Ciencias de la Salud. Zaragoza.

\section{Coordinación del proyecto}

Coordinación científica: Juan Ignacio Martín Sánchez. Instituto Aragonés de Ciencias de la Salud. Zaragoza.

Gestión administrativa: María Esther García Pomar. Instituto Aragonés de Ciencias de la Salud. Zaragoza.

Edición y difusión: María Yamina Fandos Falo, María Pilar Blas Diez. Instituto Aragonés de Ciencias de la Salud. Zaragoza. 


\section{Declaración de interés}

Los siguientes Autores han declarado ausencia de intereses:

Juan Ignacio Martín Sánchez, Silvia Vázquez Fernández del Pozo.

Los siguientes revisores externos han declarado ausencia de intereses:

Manuela Lanzuela Valero, M $^{\mathrm{a}}$ Carmen Velilla Millán 


\section{Resumen}

\section{Introducción}

El cáncer de mama es el segundo tipo de cáncer más frecuente en el mundo y el primero en mujeres, siendo también el más prevalente en todas las regiones del mundo. La incidencia en España ha aumentado de los 84,9 casos por cada 100.000 mujeres en el año 2012 a 88,3 casos en 2015. En este mismo año, fue la primera causa de defunción por cáncer entre las mujeres españolas. En Europa, entre los años 2000 a 2007, la supervivencia a 5 años se estimó en el 81,8\% (IC95\%: 81,6\% a 82,0\%), siendo para España del $82,8 \%$ (IC95\%: 81,9\% a 83,6\%).

El tratamiento conservador curativo del cáncer de mama consiste en la exéresis del tumor acompañado de tratamiento adyuvante, quimioterápico y/o radioterápico. En el caso de que se decida la aplicación de radioterapia, el tratamiento estándar es la radioterapia externa, que irradia la mama y si procede, la axila. La dosis total recomendada es de 45-50 Gy, administrados en 25 fracciones diarias (de lunes a viernes) de entre 1,8 y 2,0 Gy durante cuatro semanas y media o cinco, con una estancia de una hora o más por sesión en el centro de referencia.

La radioterapia intraoperatoria (RIO) es una técnica que, tras la exéresis del tumor, permite la administración de una única dosis de radiación ionizante en el lecho tumoral, equivalente al tratamiento estándar y en sustitución del mismo. Puede aplicarse mediante dispositivos portátiles en el mismo quirófano, con la ventaja de no tener que desplazarse al centro de referencia para cumplir con la dosificación del tratamiento estándar o evitar la radiación de tejidos sanos como corazón y pulmón.

Entre sus inconvenientes, se encuentran la falta del informe final de anatomía patológica en el momento del cierre del lecho quirúrgico, la fibrosis del tejido mamario como complicación tardía y la ausencia de una definición estandarizada para seleccionar a las pacientes más adecuadas.

En este informe se analiza la efectividad y seguridad de la RIO como tratamiento adyuvante a la cirugía conservadora del cáncer de mama en estadios tempranos y como alternativa sustitutoria a la radioterapia externa (EBRT) tras la resección del tumor. 


\section{Objetivos}

Evaluar la efectividad de la RIO en el tratamiento del cáncer de mama en términos de recurrencia, supervivencia, resultados estéticos, satisfacción de las pacientes e impacto en su calidad de vida.

Comparar la seguridad en términos de toxicidad de la RIO frente al tratamiento radioterápico estándar.

Definir qué subgrupos de mujeres con cáncer de mama pueden beneficiarse más del tratamiento con RIO.

\section{Metodología}

Se consultaron diversas bases de datos especializadas en revisiones sistemáticas, bases de datos generales, de proyectos de investigación en curso y páginas web de Agencias de Evaluación de Tecnologías Sanitarias y de INAHTA.

Se seleccionaron, para su lectura a texto completo, estudios por título y resumen. Tras lectura a texto completo, se incluyeron los que cumplían los criterios de inclusión, y se listaron los excluidos y motivos que lo justificaron.

Entre los criterios de inclusión, se contemplaron el diseño de los estudios, tamaño muestral, características de las pacientes, tipo de intervención, de seguimiento y medición de resultados (recurrencia ipsilateral de la enfermedad, aparición de metástasis y mortalidad).

Para el análisis de la eficacia/efectividad de la RIO se utilizó el sistema GRADE, teniendo en cuenta en su evaluación: las limitaciones en el diseño de los estudios, inconsistencia entre los resultados, existencia de evidencia directa o indirecta, imprecisión de los estimadores de efecto y posible sesgo de publicación. La calidad de los estudios analizados para la eficacia/efectividad de la RIO fue evaluada mediante la herramienta de lectura crítica desarrollada por Osteba.

Para el resto de cuestiones, dada la baja calidad de los estudios identificados, su heterogeneidad clínica y metodológica, no se utilizó el sistema GRADE.

\section{Resultados}

Identificados 808 estudios, tras eliminar por título y resumen y duplicados, se revisaron a texto completo 125 trabajos, de los que se seleccionaron 37. 
Con una heterogeneidad estadística alta $\left(\mathrm{I}^{2}=81 \%\right)$, el riesgo de recurrencias ipsilaterales de la neoplasia fue 4 veces mayor tras la administración de RIO que tras la administración de EBRT con un RR: 4,11 (IC95\%: 0,99 a 17,13), obtenido a partir de 2 estudios (4.680 mujeres, 73 eventos) con riesgo elevado de sesgos por falta de enmascaramiento de las mujeres participantes y personal del estudio a las intervenciones realizadas y a la evaluación de resultados. No se identificaron tampoco diferencias estadísticamente significativas para la aparición de metástasis, mortalidad por cáncer de mama (ambas sin heterogeneidad estadística), mortalidad global y mortalidad por otras causas.

Las lesiones y manifestaciones dérmicas tras cirugía y radioterapia (7 estudios), fueron estadísticamente significativas (análisis por protocolo de 2 estudios) más frecuentes tras EBRT.

De las complicaciones parenquimatosas tras cirugía y radioterapia (21 estudios), en dos estudios se puso de manifiesto que la necrosis grasa era, de manera estadísticamente significativa, más frecuente tras RIO, y en uno de ellos la aparición de hematomas o seromas.

A partir de un estudio, se describe un mayor incremento de la densidad radiológica mamaria y engrosamiento de la piel, de manera estadísticamente significativa, tras la administración de EBRT (141 mujeres, 31 eventos y 36 eventos, seguimiento de 4 y 5 años respectivamente).

La administración de RIO supone emplazar adecuadamente el emisor de radiaciones. Hay autores que estiman hasta en un $25 \%$ de los casos un mal posicionamiento del emisor o la presencia de tumor residual en el tejido adyacente.

De una muestra de 81 mujeres estadounidenses informadas, 7 optaron por la EBRT aunque esta técnica pudiera presentar más riesgos que la RIO, 22 se decantaron por RIO a igual riesgo que EBRT y 52 eligieron la RIO aun asumiendo un mayor riesgo de recidiva que con EBRT (riesgo de recidiva del 2,3\% superior respecto a EBRT).

En profesionales sanitarios (110) australianos que trabajan con mujeres diagnosticadas de cáncer de mama, se investigó el incremento máximo de riesgo de recurrencia local que estaban dispuestos a aceptar de la RIO para optar por la RIO en lugar de la EBRT, asumiendo que la decisión no tenía impacto en la supervivencia global. Casi un $60 \%$ optaría por RIO asumiendo un riesgo de recurrencia entre un $1 \%$ y $3 \%$, mientras que algo más del $3 \%$ nunca optaría por la RIO.

6 estudios valoran los resultados estéticos con RIO e informados por los clínicos con resultados excelentes o buenos en el $90 \%$ de los casos o más. En uno de los estudios se muestran desagregadas las valoraciones realizadas 
por las pacientes, con resultados excelentes o buenos en casi el $86 \%$ de los casos y con un seguimiento de 5 años.

La calidad de vida percibida por las mujeres sobre los síntomas mamarios fue estadísticamente significativa hasta los 5 años de seguimiento a favor de la RIO, y clínicamente significativas hasta el año tras tratamiento. Tanto la función como la satisfacción sexual fueron informadas tanto clínica como estadísticamente significativas a favor de la RIO hasta los 5 y 4 años tras el tratamiento respectivamente.

A partir de un estudio realizado en EEUU sobre seguridad radiológica del personal sanitario, se concluye que el dispositivo emisor puede ser utilizado en quirófanos estándar y que el personal debe protegerse con delantales plomados durante la emisión de radiaciones a una distancia mínima de 1 metro de la mesa de tratamiento.

Para la evaluación económica de la RIO, se requiere de un mayor tiempo de seguimiento de las mujeres, de la creación de registros que puedan nutrir el desarrollo posterior de modelos económicos más robustos, dada la inconsistencia actual al respecto.

\section{Conclusiones}

En el manejo conservador del cáncer de mama temprano, si la opción terapéutica adyuvante es la radioterapia, el estándar es la aplicación de EBRT.

La RIO se presenta como alternativa de sustitución de la EBRT en mujeres con cáncer de mama en estadios iniciales y de bajo riesgo de recurrencias (mujeres con tumores de $2 \mathrm{~cm}$ o menos, menos de 4 ganglios linfáticos positivos, tumores diferenciados, receptor estrogénico positivo y tumor de mama triple positivo).

En mujeres con cáncer de mama en estadios iniciales, transcurridos 5 años desde la intervención, la tasa de recurrencias ipsilaterales de la RIO es mayor, siendo estadísticamente significativa a partir del análisis individual de los estudios, y no significativa al metaanalizar los datos. Desde una perspectiva de no inferioridad, para este mismo desenlace, la RIO se muestra equivalente a la EBRT.

En mujeres con las mismas características, al comparar la RIO con la EBRT, no se observan diferencias estadísticamente significativas en términos de mortalidad ni aparición de metástasis.

La aparición de eventos adversos sobre la piel de la mama es más frecuente con el uso de EBRT, sin que se encuentren diferencias en la aparición de fibrosis, retracción de la mama, dolor o sensación de quemazón. La 
aparición de necrosis grasa y hematomas-seromas que precisan de drenaje se asocia con mayor frecuencia al uso de la RIO.

Tanto las mujeres como los profesionales sanitarios encuestados sobre su preferencia por la RIO frente a la EBRT, asumiendo un riesgo de recidiva local algo mayor con RIO y sin ver alterada la supervivencia global, mayoritariamente optaron por RIO. Entre un $8,6 \%$ de las mujeres y un $3,3 \%$ de los profesionales sanitarios, nunca optarían por RIO.

Los resultados estéticos pueden estar sobrevalorados, esencialmente por estar informados y evaluados por los propios profesionales sanitarios.

La calidad de vida no se ve afectada tras la aplicación de una técnica u otra, salvo las diferencias clínicas a favor de la RIO que, transcurrido el primer año tras la intervención, se igualan a la EBRT. Tanto la función como la satisfacción sexual muestran mejores resultados tras RIO durante los primeros 4 a 5 años de seguimiento.

Los centros que actualmente ofrecen la RIO, deben realizarlo bajo protocolos institucionales, y asegurar la participación activa de la mujer en la toma de decisiones tras ser informada del riesgo de recurrencias, seguridad de la técnica, ventajas y limitaciones, resultados estéticos y experiencias previas de mujeres sobre calidad de vida percibida. Esta información puede ser proporcionada apoyándose en recursos de información que incluyan herramientas gráficas.

Los profesionales sanitarios implicados en la aplicación de la técnica deben seguir las medidas de protección radiológicas que incluyen, el uso de delantales plomados en quirófano y mantener la máxima distancia posible al foco emisor de radiaciones.

Se deben desarrollar modelos económicos que tengan en cuenta los costes asociados al manejo de las recurrencias tras el uso de la RIO, la toxicidad y el coste adicional que supone la existencia no detectada previamente de ganglios positivos. 



\section{Summary}

\section{Introduction}

Breast cancer is the second most common cancer in the world and the first in women, being also the most prevalent in all regions of the world. The incidence in Spain has increased from 84.9 cases per 100,000 women in 2012 to 88.3 cases in 2015. In this same year, it was the leading cause of death from cancer among Spanish women. In Europe, between the years 2000 to 2007, 5-year survival was estimated at $81.8 \%$ (95\%CI: $81.6 \%$ to $82.0 \%$ ), with $82.8 \%$ for Spain (95\% CI: $81.9 \%$ to $83.6 \%$ ).

The conservative curative treatment of breast cancer is surgical removal of tumor with additional use of adjuvant chemotherapy and / or radiotherapy treatment. In the cases which the application of radiotherapy is decided, the standard treatment involves external radiotherapy, which consist in irradiation of the breast and, if it is necessary involves the axilla. The total recommended dose is $45-50 \mathrm{~Gy}$, administered in 25 daily fractions (from Monday to Friday) between 1.8 and 2.0 Gy (4.5 to 5 weeks), with a stay of one hour or more per session in the reference center.

Intraoperative radiotherapy (IOR) is a technique that, after the surgical removal of the tumor, allows the administration of a single dose of ionizing radiation in the tumor bed, equivalent to the standard treatment and in substitution of it. It can be applied by portable devices in the same operating room, with the advantage of not having to travel to the reference center to comply with the standard treatment dosage or to avoid radiation of healthy tissues such as heart and lung. Among its drawbacks, one of them is the lack of the final report of pathology diagnosis at the time of closure of the surgical site, the fibrosis of the mammary tissue as a late complication and the absence of a standardized definition to select the most appropriate patients.

This report analyzes the efficacy and safety of IOR as an adjuvant treatment to conservative breast cancer surgery in the early stages and as a substitute alternative to external radiotherapy (EBRT) after removal of the tumor.

\section{Objectives}

To evaluate the effectiveness of the IOR in the treatment of breast cancer in terms of recurrence, survival, cosmetic results, patient satisfaction and impact on their quality of life. 
To compare the safety of IOR versus standard radiotherapy treatment in terms of toxicity.

To define which subgroups of women with breast cancer may benefit more from treatment with IOR.

\section{Methods}

Various databases specialized in systematic reviews, general databases, ongoing research projects and web pages of Health Technology Assessment Agencies and INAHTA were consulted.

The studies by title and abstract were selected for reading in full text. After reading the full text, those that fulfilled the inclusion criteria were included, and those excluded and reasons that justified it were listed.

Among the inclusion criteria, the design of the studies, sample size, characteristics of the patients, type of intervention, follow-up and measurement of results (ipsilateral recurrence of the disease, appearance of metastasis and mortality) were contemplated.

The GRADE system was used to analyze the effectiveness of the IOR, taking into account the limitations in the design of the studies, inconsistency between the results, existence of direct or indirect evidence, imprecision of the estimators of effect and possible publication bias. The quality of the studies analyzed for the effectiveness of the IOR was evaluated through the critical reading tool developed by Osteba.

For the remaining questions, given the low quality of the studies identified, their clinical and methodological heterogeneity, the GRADE system was not used.

\section{Results}

808 studies were identified, after eliminating by title and summary and duplicates, 125 papers were reviewed in full text, of which 37 were selected.

With a high statistical heterogeneity $\left(\mathrm{I}^{2}=81 \%\right)$, the risk of ipsilateral recurrences of the neoplasm was 4 times higher after the administration of IOR than after the administration of EBRT with a RR: 4.11 (95\% CI: 0.99 a 17.13), obtained from 2 studies (4,680 women, 73 events) with a high risk of bias due to lack of masking of the women and study staff participants to the interventions carried out and the evaluation of results. No statistically significant differences were identified for the appearance of metastasis, 
mortality from breast cancer (both without statistical heterogeneity), global mortality and mortality from other causes.

The lesions and skin signs and sumptoms after surgery and radiotherapy (7 studies) were statistically significant (analysis by protocol of 2 studies) more frequent after EBRT.

Of the parenchymal complications after surgery and radiotherapy (21 studies), two studies showed that fat necrosis was statistically significant, more frequent after IOR, and in one of them the appearance of hematomas or seromas.

From a study, a greater increase in mammary radiological density and thickening of the skin was described, in a statistically significant way, after the administration of EBRT (141 women, 31 events and 36 events, followup of 4 and 5 years respectively).

The administration of IOR supposes to place adequately the balloon applicator. Some authors estimate that poor positioning of the transmitter or the presence of residual tumor in adjacent tissue occurs in up to $25 \%$ of cases.

From a sample of 81 American women informed, 7 opted for the EBRT although this technique could present more risks than the IOR, 22 opted for IOR at the same risk as EBRT and 52 chose the IOR even assuming a higher risk of recurrence than with EBRT (risk of relapse $2.3 \%$ higher than EBRT).

In Australian health professionals (110) working with women diagnosed with breast cancer, was investigated the maximum increase in risk of local recurrence that they were willing to accept from the IOR, in order to opt for the IOR instead of the EBRT, assuming that the decision it had no impact on overall survival. Almost $60 \%$ would opt for IOR assuming a recurrence risk between $1 \%$ and $3 \%$, while slightly more than $3 \%$ would never opt for the IOR.

6 studies assess cosmetic results with IOR and informed by clinicians with excellent or good results in $90 \%$ of cases or more. In one study is disaggregated the assessments made by the patients, with excellent or good results in almost $86 \%$ of cases and with a follow-up of 5 years.

The quality of life perceived by women on breast symptoms was statistically significant up to 5 years of follow-up in favor of the IOR, and clinically significant up to one year after treatment. Both function and sexual satisfaction were reported both clinically and statistically significant in favor of the IOR until 5 and 4 years after treatment respectively.

Based on a study carried out in USA on radiological safety of health professionals, it concludes that the emitting device can be used in standard 
operating rooms and that personnel should be protected with lead aprons during radiation emission at a minimum distance of 1 meter from the treatment table.

For the economic evaluation of the IOR, it is necessary to have a longer follow-up time of the women, to create a registers that can nourish the subsequent development of more robust economic models, given the current inconsistency existing.

\section{Conclusions}

In the conservative management of early breast cancer, if the adjuvant therapeutic option is radiotherapy, the standard option is the application of EBRT.

The IOR is presented as an alternative to the substitution of EBRT in women with breast cancer in early stages and at low risk of recurrence (women with tumors of $2 \mathrm{~cm}$ or less, less than 4 positive lymph nodes, differentiated tumors, positive estrogen receptor and triple positive breast tumor).

In women with breast cancer in the early stages, 5 years after the intervention, the rate of ipsilateral recurrence of the IOR is higher, being statistically significant from the analyzes of the individual studies, and not significant when meta-analyzing the data. From a non-inferiority perspective, the IOR is equivalent to the EBRT.

In women with the same characteristics, when comparing IOR with EBRT, no statistically significant differences were observed in terms of mortality or appearance of metastasis.

The occurrence of adverse events on the skin of the breast are more frequent with the use of EBRT, without differences being found in the appearance of fibrosis, breast retraction, pain or burning sensation. The appearance of fat necrosis and hematomas-seromas that require drainage is most frequently associated with the use of IOR.

Both the women and the health professionals surveyed on their preference for the IOR versus the EBRT, assuming a risk of local recurrence somewhat greater with IOR and without seeing the overall survival modified, mostly opted for IOR. Between $8.6 \%$ of women and $3.3 \%$ of health professionals, they would never opt for IOR.

The cosmetic results may be overestimated essentially because they are informed by the health professionals themselves.

The quality of life is not affected after the application of one or another technique, except for the clinical differences in favor of the IOR 
during the first year, after which they are equal to the results obtained with EBRT. Both function and sexual satisfaction show better results after IOR during the first 4 to 5 years of follow-up.

The centers that currently offer the RIO, must do it under institutional protocols, and ensure the active participation of women in decision making after being informed of the risk of recurrences, safety of the technique, advantages and limitations, cosmetic results and previous experiences of women on perceived quality of life. This information can be provided by relying on information resources that include graphic tools.

Health professionals involved in the application of the technique should follow the radiological protection measures that include the use of leaded aprons in the operating room and maintain the maximum possible distance to the radiation source.

Economic models should be developed that take into account the costs associated with the management of recurrences after the use of the IOR, the toxicity and the additional cost associated with previously undetected positive lymph nodes. 



\section{Abreviaturas}

3D-CRT: 3 Dimensional Conformal RadioTherapy

APBI: $\quad$ Accelerated Partial-Breast Irradiation

AVAC: $\quad$ Años de vida ajustados según la calidad

cm: centímetros

EBRT: $\quad$ Radioterapia Externa -External Beam RadioTherapy

ECA: $\quad$ Ensayo Clínico Aleatorizado

Fr: $\quad$ Fracciones

Gy: $\quad$ Gray (unidad de radiación)

HER2 (ErBB2): Receptor para el factor de crecimiento de tipo epidérmico humano

HR: $\quad$ Hazard Ratio

IC95\%: $\quad$ Intervalo de confianza al $95 \%$

IMRT: Intensity-Modulated Radiation Therapy

Kv: Kilovoltio

min: minuto

ML: $\quad$ Multi Lumen

$\mu \mathrm{R}: \quad$ microRoentgen

mR: miliRoentgen

mSv: miliSievert

QUALY: Quality-Adjusted Life Year

RCEI: Ratio Coste Efectividad Incremental

RT: Radioterapia

RIO: $\quad$ Radioterapia IntraOperatoria 



\section{Glosario}

Año oficial: periodo de doce meses, a contar desde el día 1 de enero hasta el 31 de diciembre, ambos inclusive.

Años de vida ajustados según la calidad - AVAC: es una medida del estado de la salud, que considera tanto la cantidad como la calidad de vida. Se utiliza en la evaluación económica para valorar la rentabilidad de las intervenciones médicas. Un AVAC equivale a un año en perfecto estado de salud. Si la salud de un individuo está por debajo de este máximo, los AVACs se acumulan a una tasa de menos de 1 por año. Donde estar muerto se asocia con 0 AVACs. Los AVACs se pueden utilizar para informar decisiones personales, evaluar programas de salud y establecer prioridades para futuros programas.

Diferencia Mínimamente Importante: desde el punto de vista médico, se entiende como significación clínica, es decir, "la diferencia más pequeña entre las puntuaciones del dominio de interés que los pacientes perciben como beneficiosa y que podría aconsejar, en ausencia de efectos secundarios indeseables y coste excesivo, un cambio en el tratamiento del paciente".

Dosis efectiva: suma de las dosis equivalentes ponderadas en todos los tejidos y órganos del cuerpo a causa de irradiaciones internas y externas. $\mathrm{La}$ Unidad para la dosis efectiva es el Sievert.

Dosis equivalente: dosis absorbida, en el tejido u órgano, ponderada en función del tipo y la calidad de la radiación.

Radiación ionizante: transferencia de energía en forma de partículas u ondas electromagnéticas de una longitud de onda igual o inferior a 100 nanómetros o una frecuencia igual o superior a 3×1015 hertzios, capaces de producir iones directa o indirectamente.

Sievert: nombre especial de la unidad de dosis (radiaciones ionizantes) efectiva y equivalente. Un Sievert es igual a un julio por kilogramo. 



\section{Introducción y justificación}

El cáncer de mama es el segundo tipo de cáncer más frecuente en el mundo, y el más frecuente en mujeres, con una estimación de 2,09 millones de nuevos casos diagnosticados en 2018 (11,6\% de todos los cánceres). Se trata del cáncer más prevalente en mujeres, en todas las regiones del mundo. Esta prevalencia es mayor en las regiones del mundo menos desarrolladas, con un número de casos más elevado en localizaciones menos desarrolladas (1.279.438 casos) respecto a las más desarrolladas (809.411 (asos) $)^{1}$.

La tasa de incidencia varía entre distintas regiones del mundo, observándose tasas entre 26 y 30 por cada 100.000 mujeres en el este y centro de África y sudeste de Asia, hasta cifras superiores a 92 casos por 100.000 mujeres en el oeste de Europa, Australia y Nueva Zelanda, lo que representa una variación en su magnitud casi cuatro veces superior ${ }^{1}$.

En España y respecto a Europa, la incidencia del cáncer de mama en el año 2012 se situó en torno a los 84,9 casos/100.000 mujeres 2 , siendo en el año 2015 en torno a 88,3 casos/100.000 mujeres (IC95\%: 76,1 a 102,1)3.

En España, el cáncer de mama supuso en el año 2015 el 14,2\% de las defunciones por cáncer (6.212), siendo la primera causa de fallecimiento entre las mujeres, con unas tasas de mortalidad ajustadas con población europea y mundial de 15,71 por cada 100.000 y 10,81 por cada 100.000 respectivamente 4 .

La supervivencia del cáncer de mama ha aumentado progresivamente en los países desarrollados, con cifras que alcanzan el $85 \%$ a los 5 años 2 . En Europa, para las mujeres diagnosticadas en el periodo comprendido entre el año 2000 y 2007, la supervivencia se situó en el 81,8 \% (IC95\%: 81,6\% a 82,0\%), siendo en España del 82,8\% (IC95\%: 81,9\% a 83,6\%) 5 . Ello se debe fundamentalmente a mejoras en el abordaje en el cribado, diagnóstico y arsenal terapéutico. Las cifras de supervivencia en países en vías de desarrollo se mantienen en torno al $40 \%-50 \%^{2}$.

La opción terapéutica conservadora e inicial del cáncer de mama temprano es la cirugía (lumpectomía). Si los resultados permiten evitar la mastectomía, aquella puede acompañarse de un tratamiento adyuvante que, en función de los factores pronóstico y predictivos así como de la opinión y preferencias de la mujer, puede consistir en la administración de quimioterapia o radioterapia, tan pronto como sea posible. En este último caso, el tratamiento estándar es la radioterapia externa ${ }^{6}$. 
El tratamiento con radioterapia (RT) consiste en el uso de radiaciones ionizantes con fines terapéuticos, para eliminar el conjunto de células neoplásicas, mediante la reducción del tamaño del tumor y que complementa a otro tipo de intervenciones, o con carácter paliativo. En este último caso, el objetivo principal es mejorar la calidad de vida de la mujer y reducir los síntomas de una enfermedad avanzada ${ }^{2}$.

La radioterapia como tratamiento estándar (radioterapia externa) en el cáncer de mama, consiste en la aplicación de radiaciones ionizantes a toda la mama, desde una fuente externa, en los casos tratados con cirugía conservadora. Si la indicación de radioterapia es tras mastectomía, las radiaciones se aplican a la pared torácica. En los casos que han requerido la práctica de linfadenectomía axilar, se valora también su administración al área axilar².

La dosis total recomendada es de 45-50 Gy, administrados en 25 fracciones diarias (de lunes a viernes) de entre 1,8 y 2,0 Gy durante cuatro semanas y media o cinco. Cada sesión dura unos pocos minutos, aunque la estancia en la Unidad puede prolongarse durante una hora o más por sesión ${ }^{2}$.

En ocasiones, se añade a lo anterior, dosis adicionales de radiación en el lecho del tumor, bien mediante un haz externo, generalmente de electrones, o mediante el uso de implantes radioactivos intersticiales entre 10 a 16 $\mathrm{Gy}^{7}$.

El objetivo de la radioterapia como terapia adyuvante es la erradicación de enfermedad residual, reduciendo así, el riesgo de recurrencia local7.

La radioterapia intraoperatoria (RIO) se aplica combinada con la resección quirúrgica del tumor, quimioterapia (si se considera adecuada) y radiación externa ${ }^{2}$. En este caso, se añade al tratamiento de aquellas pacientes con un riesgo elevado de recurrencias (por ejemplo, tras anatomía patológica que muestra un carcinoma lobular invasivo, grado 3 o afectación ganglionar $)^{6}$. Su empleo junto con radioterapia externa, permite un incremento de la dosis de radiación y aumentar los márgenes de seguridad y limitar el riesgo de recidivas marginales, dado que los márgenes aplicados con RIO son intrínsecamente menores 2 .

La radioterapia intraoperatoria (RIO) es una técnica que ofrece la posibilidad de administrar, en estadios limitados del cáncer de mama y durante la intervención quirúrgica, una única dosis de radiación ionizante, equivalente al tratamiento estándar, directamente sobre la cavidad quirúrgica, con el objetivo de mejorar el control local de la enfermedad y disminuir la toxicidad propia de las radiaciones ionizantes, al limitar la irradiación de tejidos sanos ${ }^{2}$, en sustitución del tratamiento estándar. 
La RIO puede aplicarse, ante la indicación de tumorectomía, desde un dispositivo portátil (Intrabeam ${ }^{\circledR}$ o Axxent ${ }^{\circledR}$ ) que utiliza rayos X de $50 \mathrm{kV}$ tras la exéresis del tumor.

Si la decisión terapéutica es la realización de una cuadrantectomía, la RIO puede aplicarse desde otros dispositivos portátiles (Liac ${ }^{\circledR}$, Mobetron $^{\circledR}$, Novac-7® o Elekta SL) que utilizan haces de electrones de 3 a $10 \mathrm{MeV}$ (megaelectronvoltio).

La RIO ofrece una serie de ventajas, entre las que se destacan la posibilidad de excluir del campo de irradiación aquellos tejidos libres de enfermedad como pulmón o corazón y reducir el tiempo entre intervención quirúrgica y administración de radioterapia. Entre sus inconvenientes, destacar que aunque se puede contar con información preliminar sobre la afectación de los márgenes de resección y ganglios linfáticos, no se puede disponer en el mismo acto quirúrgico del informe final anátomo-patológico 2,8 , la aparición de fibrosis como manifestación de toxicidad tardía tras el empleo de $\mathrm{RIO}^{2}$, o la ausencia de una definición estandarizada para seleccionar a las pacientes adecuadas9.

Por tanto, se mantienen las dudas sobre el impacto de la RIO en la morbi-mortalidad y calidad de vida de las mujeres con cáncer de mama, por lo que se ve necesaria una revisión sistemática, que permita el análisis de nuevos estudios publicados 10,11 posteriores a los incorporados en el informe de Avalia-t del año $2013^{2}$ y se incluye en la búsqueda la identificación de trabajos que evalúen la perspectiva de la mujer en la adopción de medidas terapéuticas ${ }^{12}$. En el presente informe, se analiza exclusivamente la administración de RIO con fines curativos como alternativa a la técnica estándar de cirugía conservadora seguida de radioterapia externa. 



\section{Objetivos}

Evaluar la efectividad de la RIO en el tratamiento del cáncer de mama en términos de recurrencia, supervivencia, resultados estéticos, satisfacción de las pacientes e impacto en su calidad de vida.

Comparar la seguridad en términos de toxicidad de la radioterapia intraoperatoria frente al tratamiento radioterápico estándar.

Definir qué subgrupos de mujeres con cáncer de mama pueden beneficiarse más del tratamiento con RIO. 



\section{Metodología}

\section{Búsqueda bibliográfica}

Se realizó la búsqueda bibliográfica desde febrero de 2013, momento en el que se cerró la búsqueda del informe previo, elaborado por Avalia-t², a la actualidad.

Se crearon sistemas de alerta para poder incorporar todas las publicaciones pertinentes durante la elaboración del informe.

Las bases de datos consultadas son:

- Bases de datos especializadas en revisiones sistemáticas: CRD (Centre for Reviews and Dissemination) que incluye, HTA (Health Technology Assessment), DARE (Database of Abstracts of Reviews of Effectiveness) y NHS EED (Economic Evaluation Database del National Health Service) y The Cochrane Library.

- Bases de datos generales: Medline, Embase, ISI Web of Knowledge (Institute for Scientific Information) e IME (Índice Médico Español).

- Bases de datos de proyectos de investigación en curso: Clinical Trials Registry (US. National Institutes of Health), Current Controlled Trials, International Standard Randomised Controlled Trial Number Register (ISRCTN), International Clinical Trials (WHO), European Union Clinical Trials Register.

- $\quad$ Páginas web de las Agencias de Evaluación de Tecnologías sanitarias, así como la de la red INAHTA.

Se adaptó el lenguaje de las estrategias de búsqueda a cada base de datos, combinando descriptores y términos libres.

Se seleccionaron inicialmente, para su lectura a texto completo, los estudios por su título y resumen, tras eliminar los duplicados. A partir de los estudios revisados a texto completo, se seleccionaron aquellos que cumplían los criterios de inclusión y se listaron aquellos excluidos y los motivos que lo justifican. 


\section{Criterios de selección de los estudios}

La selección de los artículos se realizó de acuerdo con el cumplimento de los criterios de inclusión y exclusión considerados.

\section{Criterios de inclusión:}

Diseño de los estudios: revisiones sistemáticas, meta-análisis, ensayos clínicos, estudios de cohortes en los que se compare esencialmente la RIO con el tratamiento estándar (cirugía conservadora seguida de radioterapia sobre toda la mama tratada durante 5-6 semanas de radioterapia externa (EBRT) y un refuerzo adicional sobre el lecho del tumor durante 1-2 semanas) o en los que se compare diferentes aplicaciones de RIO (refuerzo vs terapia exclusiva), estudios de casos y controles y series de casos.

Tamaño de la muestra: Mínimo de 30 pacientes tratados con RIO independientemente del diseño del estudio.

Características de las pacientes: pacientes adultas con cáncer de mama en cualquier estadio, sometidas a radioterapia intraoperatoria en el acto quirúrgico como sustituto de la radioterapia post-operatoria tras la cirugía y en su defecto como refuerzo.

Tipo de intervención: RIO con haz de electrones o rayos X.

Medida de resultados: mortalidad, morbilidad o la calidad de vida de las pacientes sometidas a RIO, medidas como supervivencia, control recurrencias local o a distancia, lesiones parenquimatosas y de la piel, preferencias de las mujeres, de los profesionales sanitarios, resultados estéticos, calidad de vida percibida por las mujeres, seguridad del personal sanitario y evaluación económica de la RIO.

Tiempo de seguimiento: Período de seguimiento medio o mediano de 3 meses desde que se administró el tratamiento (RIO).

Momento de la aplicación de la terapia: Estudios en los que la administración de la RIO en la mayoría de las pacientes sea posterior al año 2000.

Idioma: Castellano, inglés, francés, italiano y portugués.

Unidad de estudio: Estudios realizados exclusivamente en humanos.

\section{Criterios de exclusión:}

Diseño de los estudios: estudios de un sólo caso, revisiones narrativas, cartas al director, editoriales, comentarios comunicaciones a congresos. 
Características de las pacientes: pacientes sometidos a RIO para tratar tumores diferentes al de mama.

Tipo de intervención: radiación de fuentes internas o braquiterapia.

Medida de resultados: estudios cuya finalidad sea el cálculo de la dosis efectiva de RIO o resultados técnicos (ausencia de resultados clínicos o relacionados con los pacientes).

\section{Extracción de datos y evaluación de la calidad de los estudios}

Para el análisis de la eficacia/efectividad de la RIO frente a otras alternativas, se utilizó el sistema GRADE (Grading of Recommendations, Assessment and Evaluation) y se clasificó la calidad de la evidencia (alta, moderada, baja o muy baja) ${ }^{13}$ de cada uno de los desenlaces teniendo en cuenta los siguientes factores: limitaciones en el diseño del estudio ${ }^{14}$, inconsistencia entre los resultados de los diferentes estudios ${ }^{15}$, existencia de evidencia directa o indirecta ${ }^{16}$, imprecisión de los estimadores de efecto ${ }^{17}$, sesgo de publicación ${ }^{18}$.

Dado que los estudios incluidos fueron ensayos clínicos controlados y aleatorizados, no se tuvieron en cuenta los factores que permiten aumentar la calidad de la evidencia de estudios observacionales como son: magnitud del efecto, existencia de un gradiente dosis respuesta e impacto de las variables de confusión ${ }^{19}$.

Los datos relevantes de los estudios incluidos fueron extraídos de manera uniforme e incluidos en tablas de evidencia. La calidad de dichos estudios fue analizada utilizando, en ambos casos, la herramienta de Lectura Crítica desarrollada por Osteba 20 .

Para el estudio del resto de cuestiones analizadas en el presente informe, incluida la seguridad, no se consideró adecuado utilizar el sistema GRADE como herramienta de clasificación de la calidad de la evidencia de los estudios seleccionados, al existir gran heterogeneidad clínica y metodológica 21,22 entre los estudios incluidos. 



\section{Resultados}

Se obtuvieron 808 estudios que tras eliminar por título y resumen, así como duplicados, se revisaron a texto completo 125 estudios, de los que se seleccionaron 37.

Para el estudio de la eficacia/efectividad de la RIO se han seleccionado dos ensayos clínicos controlados y aleatorizados 10,11 (ver anexo 1).

Para el abordaje de la seguridad y efectos adversos se realiza una descripción de resultados de los 27 estudios identificados, dada la heterogeneidad clínica y metodológica de los mismos 10,11,23-47.

Se ha seleccionado un estudio sobre el abordaje de las preferencias de las mujeres ${ }^{48}$, y otros sobre las preferencias de los profesionales de la salud 49 .

Figura 1. Diagrama de flujo para la identificación y selección de estudios sobre RIO

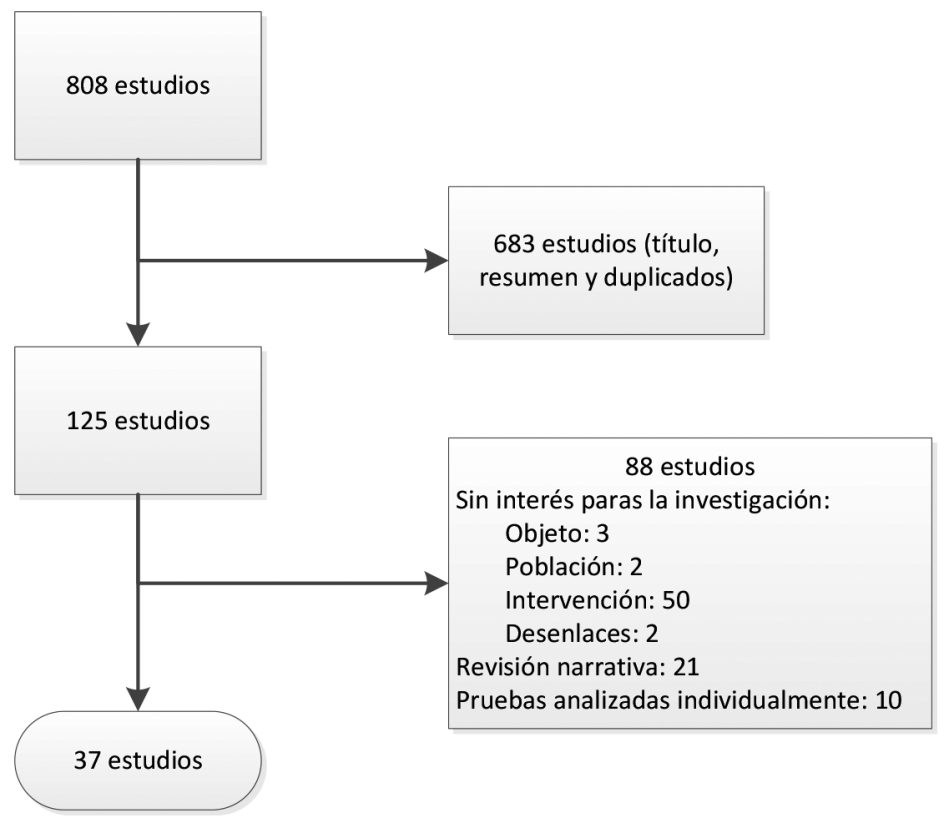


Los resultados estéticos son evaluados por 6 estudios $35,38,50-53$ y la calidad de vida percibida por las mujeres en uno de los estudios seleccionados 50 . La seguridad del personal sanitario es abordada en uno de los estudios seleccionados 54 , y la evaluación económica de la RIO por tres $6,55,56$.

\section{Eficacia/efectividad de la RIO}

Veronesi et al. 2013 ${ }^{11}$, entre noviembre de 2000 y diciembre de 2007, comparan la administración de electrones en una única sesión y dosis (21 Gy) de RT en el lecho tumoral, tras la exéresis del tumor, frente a la RT administrada mediante EBRT (50 Gy / 25 Fr + refuerzo $10 \mathrm{~Gy} / 5 \mathrm{Fr}$ ) tras cirugía, con el objetivo de identificar si la primera opción es igual de efectiva que la segunda. Seleccionan a mujeres entre 48 y 75 años, con diagnóstico de cáncer de mama temprano, tumor igual o inferior a $2,5 \mathrm{~cm}$ de diámetro y susceptible de tratamiento conservador. Para el desenlace principal (recurrencias locales a los 5 años tras tratamiento) diseñan un estudio de equivalencia, preestableciendo un margen de recurrencia inferior al 7,5\%. Observan la aparición de 35 casos de recurrencias locales en el grupo de RIO, con una tasa de eventos a los 5 años de un 4,4\% (IC95\%: $2,7 \%$ a $6,1 \%)$, dentro del margen de equivalencia pre-especificado del 7,5\%. La aparición de recurrencias locales en el grupo de EBRT fue de 4 casos, con una tasa de eventos del 0,4\% (IC95\%: 0,0\% a 1,0\%); siendo las diferencias estadísticamente significativas $(\mathrm{p}=0,0001)$. La HR para el desarrollo de una recurrencia local fue de 9,3 (IC95\%: 3,3 a 26,3) en el grupo de mujeres tratadas con RIO respecto al grupo tratado con radioterapia externa.

Al analizar los casos incidentes, se observa que el 1\% de mujeres con recidiva local en cada grupo se alcanza a los 2 años en el grupo RIO y en torno a los 7 años en el grupo EBRT. Para el resto de desenlaces (metástasis, mortalidad total, por neoplasia de mama, por otras causas), no se observaron diferencias estadísticamente significativas entre grupos.

Los autores del estudio analizaron las características del tumor en las mujeres que desarrollaron recidiva local y que recibieron RIO. Las recurrencias ipsilaterales a 5 años, en el grupo de mujeres clasificadas como de alto riesgo fue del 11,3\% (IC95\%: 6,4\% a 16,1\%) y presentaron alguna de estas características: tamaño del tumor $>$ de $2 \mathrm{~cm}, 4$ ó más ganglios linfáticos positivos, tumor escasamente diferenciado (grado 3), receptor estrogénico negativo y tumor de mama triple negativo. Estas mujeres fueron susceptibles de beneficiarse de EBRT. En las mujeres clasificadas como de bajo riesgo se observaron recurrencias ipsilaterales a los 5 años tras el tratamiento del 1,5\% (IC95\%: 0,3\% a 2,7\%), p<0,0001. 
Vaidya et al. 201410 lideran un ensayo clínico aleatorizado, pragmático y multicéntrico (11 países) que analiza la recurrencia local a los 5 años en mujeres de 45 años o más con cáncer de mama temprano. Utilizan RIO mediante la aplicación de rayos x con energía de $50 \mathrm{Kv}$ y aplicadores con diámetros entre 1,5 y $5 \mathrm{~cm}$ que emiten durante 20 a 45 min radiaciones ionizantes con una dosis de $20 \mathrm{~Gy}$ en el lecho tumoral (y dosis atenuada entre 5 y $7 \mathrm{~Gy} \mathrm{a} 1 \mathrm{~cm}$ ). Definen como desenlace principal la diferencia absoluta de recurrencias locales (preestablecen como margen absoluto de no-inferioridad un 2,5\% de diferencias). Para el grupo RIO, obtienen unas recurrencias a los 5 años del 3,3\% (IC95\%: 2,1 a 5,1) y para el grupo EBRT del 1,3\% (IC95\%: 0,7 a 2,5), no observándose diferencias estadísticamente significativas $\mathrm{p}=0,042$ (referencia para las recurrencias locales $\mathrm{p}<0,01$ ) y obteniendo una diferencia absoluta de recurrencias locales del $2 \%$ (margen de noinferioridad $=2,5 \%$ ).

No se observaron diferencias estadísticamente significativas para la mortalidad por cáncer de mama, mortalidad global o metástasis y sí para la mortalidad por otras causas (por causas cardiovasculares y otros cánceres), siendo del 1,4\% (IC95\%: 0,8 a 2,5) para el grupo RIO y del 3,5\% (IC95\%: 2,3 a 5,2) para el grupo EBRT $\mathrm{p}=0,0086$. Concluyen que la RIO en mujeres de bajo riesgo es una alternativa a la EBRT.

Se ha publicado una revisión sistemática ${ }^{57}$ que incluye y metaanaliza los resultados ofrecidos por Veronesi y Vaidya junto con otros dos estudios no aleatorizados. Dada la heterogeneidad clínica y metodológica de los estudios incluidos en dicha revisión, ésta no se ha tenido en cuenta como fuente de evidencia. En este informe se han analizado individualmente los estudios de Veronesi y Vaidya y metanalizado sus estimadores de resultados.

No se observan diferencias estadísticamente significativas para ninguno de los desenlaces analizados (recurrencias ipsilaterales a los 5 años, aparición de metástasis, mortalidad global, mortalidad por otras causas y mortalidad por cáncer de mama). La heterogeneidad estadística es baja $\left(\mathrm{I}^{2}<18 \%\right)$ para la aparición de metástasis, mortalidad global y mortalidad por cáncer de mama, moderada para la mortalidad por otras causas $\left(\mathrm{I}^{2}=49 \%\right)$ y alta para el desenlace principal $\left(\mathrm{I}^{2}=81 \%\right)$, recurrencias ipsilaterales, con un $\mathrm{RR}=$ 4,11 (IC95\%: 0,99 a 17,13) 
Figura 2. Análisis de los distintos desenlaces críticos.

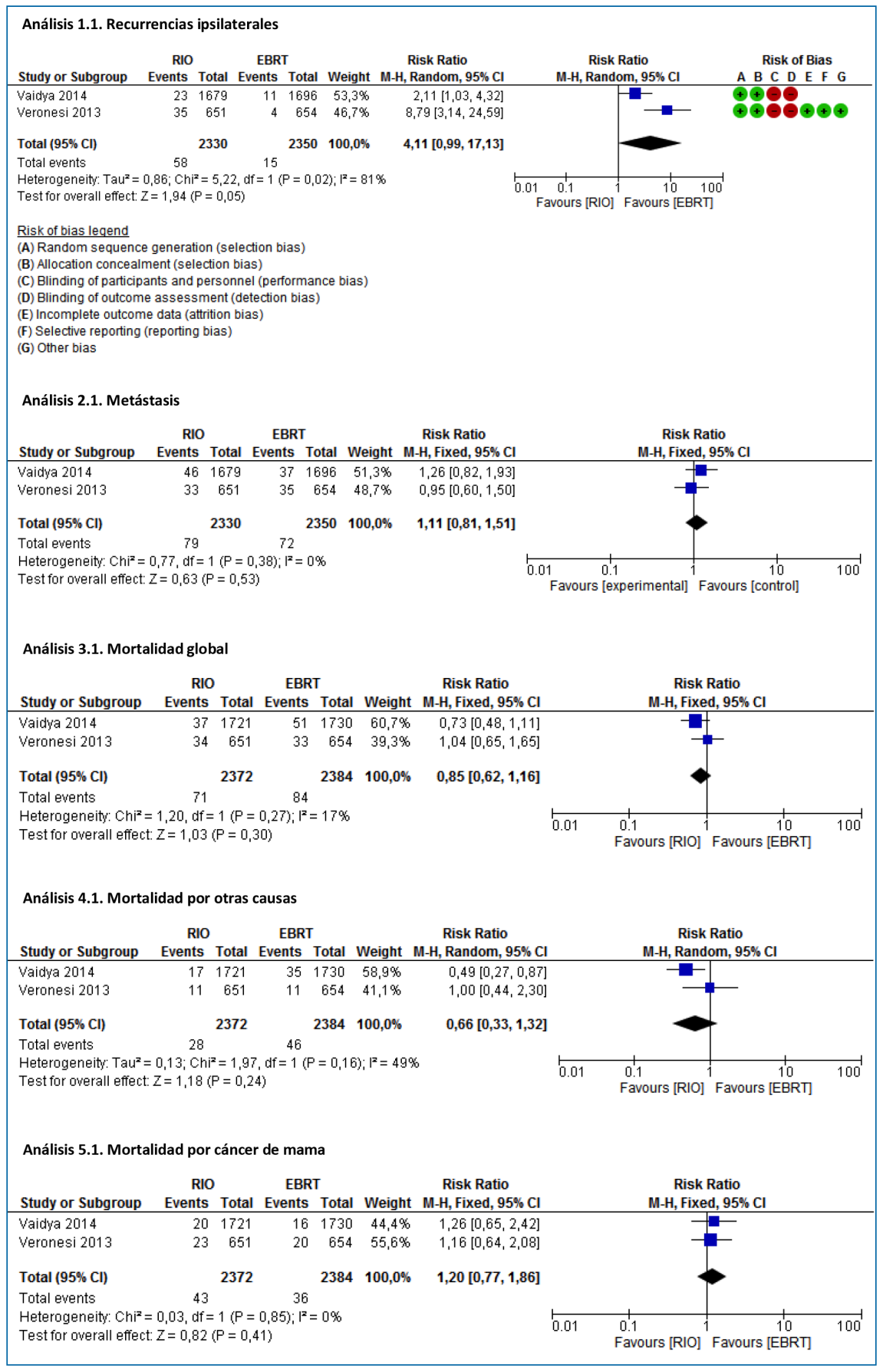




\section{Seguridad de la RIO}

Se han seleccionado 21 estudios para la descripción y análisis de la seguridad de la RIO10,11,23-41, uno específico sobre la aparición de cicatrices hipertróficas ${ }^{42}$, otro sobre seguridad cardíaca ${ }^{43}$, dos estudios que abordan el correcto posicionamiento del emisor de radiaciones 46,47 y dos estudios que debaten la aparición de segundas neoplasias 44,45 .

Algunos de los estudios diseñados con un grupo de control, se han clasificado como estudios sin grupo control, debido a que ofrecen resultados sobre seguridad de manera agregada, sin poder discernir aquellas que acontecieron en un grupo y otro $27,34,40$.

Las lesiones y manifestaciones dérmicas tras cirugía y radioterapia incluyen la aparición de eritema, sequedad, hiperpigmentación, prurito y toxicidad de la piel (ver tabla 1).

El ensayo clínico de Veronesi et al. 2013, muestra resultados sobre lesiones parenquimatosas y dérmicas con una mediana de seguimiento de 5,8 años (RIQ: 4,1 a 7,7 años) mediante un análisis por protocolo. El estudio muestra la aparición de efectos adversos, con más frecuencia y estadísticamente significativo en el grupo EBRT para las siguientes entidades en la piel: eritema, sequedad, hiperpigmentación, prurito. Sin embargo, no se observaron diferencias estadísticamente significativas en la aparición de fibrosis, retracción de la mama, dolor o sensación de quemazón (datos no mostrados en el estudio original) ${ }^{11}$.

En otro estudio y tras 6 meses de la aleatorización y seguimiento, no encontraron diferencias estadísticamente significativas para las complicaciones de herida, salvo para las de piel y relacionadas con la radioterapia (grados 3 ó 4) con 4/1721 para RIO y 13/1730 para EBRT $(\mathrm{p}=0,029)^{10}$. 
Tabla 1. Lesiones y manifestaciones dérmicas tras cirugía y radioterapia

\begin{tabular}{|c|c|c|c|c|c|c|c|}
\hline Estudio & Tipo estudio & Seguimiento & Eritema & Sequedad & Hiperpigmentación & Prurito & Toxicidad piel \\
\hline Veronesi 201311 & ECA & 5 años & $\begin{array}{c}\text { EBRT: } 40 / 47 \\
\text { RIO: } 5 / 29\end{array}$ & $\begin{array}{l}\text { EBRT: 20/148 } \\
\text { RIO: } 10 / 157\end{array}$ & $\begin{array}{l}\text { EBRT: } 36 / 174 \\
\text { RIO: } 11 / 157\end{array}$ & $\begin{array}{c}\text { EBRT: } 17 / 191 \\
\text { RIO: } 5 / 158\end{array}$ & $\begin{array}{c}\text { EBRT: } 37 / 464 \\
\text { RIO: } 11 / 412\end{array}$ \\
\hline Vaidya 201410 & ECA & 6 meses & & & & & $\begin{array}{c}\text { EBRT: } 13 / 1730 \\
\text { RIO: } 4 / 1721\end{array}$ \\
\hline Epstein 201627 & OPSCa & > 1año & $\begin{array}{l}\text { RIO-EBRT: } \\
\text { 146/702 }\end{array}$ & & RIO-EBRT: 54/702c & & \\
\hline Hanna 201431 & ESC & > 1año & $\mathrm{RIO}: 6 / 148$ & & & & \\
\hline Miglierini 201433 & OPSC & 3-4 semanas & & & & & $\mathrm{RIO}: 9 / 65$ \\
\hline Syed 201638 & OPSC & Media: 1,5 años & RIO: 20/225 & & & & \\
\hline Vinh-Hung 201439 & ORCC & $\begin{array}{c}\text { RIO: Mediana } \\
27 \mathrm{~d} \text { (rango } 13 \text { a } 70 \mathrm{~d} \text { ) } \\
\text { RIO+EBRT: Mediana } \\
40 \mathrm{~d} \text { (rango } 19 \text { a } 81 \mathrm{~d} \text { ) } \\
\text { tras fin EBRT }\end{array}$ & & $\begin{array}{c}\text { RIO: 0/52 } \\
\text { RIO+EBRT: 1/18 }\end{array}$ & & & $\begin{array}{c}\text { RIO: } 21 / 52 \\
\text { RIO+EBRT: } 7 / 18^{d}\end{array}$ \\
\hline
\end{tabular}

Resultados de la tabla en negrita (análisis por protocolo): $\mathrm{p}<0,05$

EBRT: Radioterapia Externa - External Beam RadioTherapy; ECA: Ensayo Clínico Controlado y Aleatorizado; ESC: Experimental Sin grupo Control; OPCC: Observacional

Prospectivo Con grupo Control; OPSC: Observacional Prospectivo Sin grupo Control; ORCC: Observacional Retrospectivo Con grupo Control; RIO: Radioterapia

Intraoperatoria.

a: De los 702 pacientes, 585 recibieron RIO exclusivamente. El resto, 117 (16,6\%) precisó de más cirugía y de EBRT.

b: Agudo, de aparición en el primer mes.

c: Crónico, persistente a los 6 meses.

d: En ambos casos, se han excluido aquellos casos con grado 1 (el grado 3 incluye los casos de seromas y grado 4 hematomas y dehiscencia de sutura). 
El resto de estudios se realizan sin grupo control27,31,33,38, con un número reducido de pacientes ${ }^{39} \mathrm{o}$ un periodo de seguimiento inferior a las 6 semanas 33,39 .

Otro aspecto abordado es el de las lesiones paranquimatosas de la mama que, entre otras, incluye la necrosis grasa (ver tabla 2).

El estudio de Veronesi et al. 2013 muestra un mayor número de lesiones parenquimatosas por necrosis grasa a lo largo de 5 años, en la mama de las pacientes que reciben RIO frente a las que se les aplica EBRT (22 mujeres en grupo RIO y 10 en grupo EBRT), siendo las diferencias estadísticamente significativas ${ }^{11}$.

Cracco et al. 2015, con un seguimiento de casi año y medio encuentran los mismos resultados para la necrosis grasa, siendo las diferencias estadísticamente significativas 23 .

Tras un seguimiento de 6 meses, los resultados mostrados por Vaidya et al. 201410 no aportan información sobre la necrosis grasa. Ésta es la complicación parenquimatosa más relevante de la RIO respecto a la EBRT, observada en el estudio de Veronesi11, con un seguimiento de 5 años. En el trabajo de Vaidya no se observan diferencias estadísticamente significativas entre una intervención y otra para otros desenlaces como la aparición de hematomas o seromas que requieren drenaje, infección de herida quirúrgica o el retraso en la cicatrización ${ }^{10}$. 
Tabla 2. Complicaciones parenquimatosas tras cirugía y radioterapia

\begin{tabular}{|c|c|c|c|c|c|c|c|c|c|}
\hline Estudio & $\begin{array}{c}\text { Tipo } \\
\text { estudio }\end{array}$ & Seguimiento & Fibrosis & $\begin{array}{c}\text { Retracción } \\
\text { mamaria }\end{array}$ & $\begin{array}{c}\text { Necrosis } \\
\text { grasa }\end{array}$ & $\begin{array}{c}\text { Hematoma / } \\
\text { seroma }\end{array}$ & Infeccióne & $\begin{array}{l}\text { Cicatrización } \\
\text { retardada }\end{array}$ & Calcificaciones \\
\hline $\begin{array}{l}\text { Veronesi } \\
2013^{11}\end{array}$ & ECA & 5 años & & & $\begin{array}{c}\text { EBRT: } \\
\text { 10/146 } \\
\text { RIO: } 22 / 151\end{array}$ & & & & \\
\hline Vaidya 201410 & ECA & 6 meses & & & & $\begin{array}{c}\text { EBRT: } 2 / 1730 \\
\text { RIO: } 4 / 1721\end{array}$ & $\begin{array}{l}\text { EBRT: } 9 / 1730 \\
\text { RIO: } 12 / 1721\end{array}$ & $\begin{array}{c}\text { EBRT: } 5 / 1730 \\
\text { RIO: } 3 / 1721\end{array}$ & \\
\hline Cracco $2015^{23}$ & ECC & 17 meses & & & $\begin{array}{c}\text { EBRT: } \\
\text { 2/105 } \\
\text { RIO: } 10 / 81\end{array}$ & $\begin{array}{c}\text { EBRT: 9/105 } \\
\text { RIO: } 6 / 81\end{array}$ & & & \\
\hline Ebner 201624 & ORCC & $\begin{array}{c}6 \text { días (Volumen } \\
\text { en } \mathrm{mL} \text {. Mediana y } \\
\text { rango) }\end{array}$ & & & & $\begin{array}{c}\text { Cirugía: } 50 \text { (2 } \\
\text { a 343) } \\
\text { Con RIO: } 50 \\
\text { (15 a 304) }\end{array}$ & & & \\
\hline $\begin{array}{l}\text { Elsberger } \\
201425\end{array}$ & OPCC & $\begin{array}{c}\text { EBRT: } \approx 4 \text { años } \\
\mathrm{RIO}: \approx 5 \text { años }\end{array}$ & & $\begin{array}{c}\text { EBRT: } 63 / 80 \\
\text { RIO: } 47 / 61\end{array}$ & & & & & $\begin{array}{l}\text { EBRT: } 19 / 80 \\
\text { RIO: } 12 / 61\end{array}$ \\
\hline Engel 201326 & ORCC & $\begin{array}{c}\text { EBRT: } M 4 a \text { (r: } 3 \\
\text { a 6,5) } \\
\text { RIO: } M \text { 4,5a (r: } 3 \\
\text { a 8) }\end{array}$ & & & $\begin{array}{c}\text { EBRT: } 5 / 21 \\
\text { RIO+EBRT: } \\
\text { 5/10 } \\
\text { RIO: } 10 / 17 \\
\end{array}$ & $\begin{array}{c}\text { EBRT: O/21 } \\
\text { RIO+EBRT: } \\
\text { 4/10 } \\
\text { RIO: } 1 / 17 \\
\end{array}$ & & & $\begin{array}{c}\text { EBRT: } 4 / 21 \\
\text { RIO+EBRT: } \\
6 / 10 \\
\text { RIO: } 11 / 17\end{array}$ \\
\hline Epstein 201627 & OPSC & $\begin{array}{l}\text { > } 1 \text { año (702 } \\
\text { pacientes, } 585 \\
\text { recibieron RIO y } \\
\text { resto, } 117 \text { precisó } \\
\text { más cirugía y } \\
\text { EBRT. }\end{array}$ & $\begin{array}{l}\text { RIO- } \\
\text { EBRT: } \\
\text { 70/702f }\end{array}$ & & $\begin{array}{c}\text { RIO-EBRT: } \\
\text { 1/702 } \\
\text { (precisa } \\
\text { cirugía) }\end{array}$ & $\begin{array}{c}\text { RIO-EBRT: } \\
\text { 12/702g } \\
\text { RIO-EBRT: } \\
\text { 16/702f }\end{array}$ & $\begin{array}{c}\text { RIO-EBRT: } \\
\text { 8/702 }\end{array}$ & & \\
\hline Falco 201628 & ORCC & M 24m (r: 7 a 52m) & & & & $\begin{array}{c}\text { RIO+EBR: } \\
\text { 14/69 } \\
\text { RIO: } 2 / 51\end{array}$ & & & \\
\hline $\begin{array}{l}\text { Fernández } \\
201629\end{array}$ & OPSC & $\approx 1$ año & & & & $\mathrm{RIO}: 5 / 86$ & & & \\
\hline Gunay 201630 & OPSC & $\begin{array}{c}\text { M } 26 \text { sem (3 sem } \\
\text { a } 13 \mathrm{~m})\end{array}$ & & & $\mathrm{RIO}: 2 / 30$ & $\mathrm{RIO}: 2 / 30$ & & & \\
\hline
\end{tabular}


Tabla 2. Complicaciones parenquimatosas tras cirugía y radioterapia (cont.)

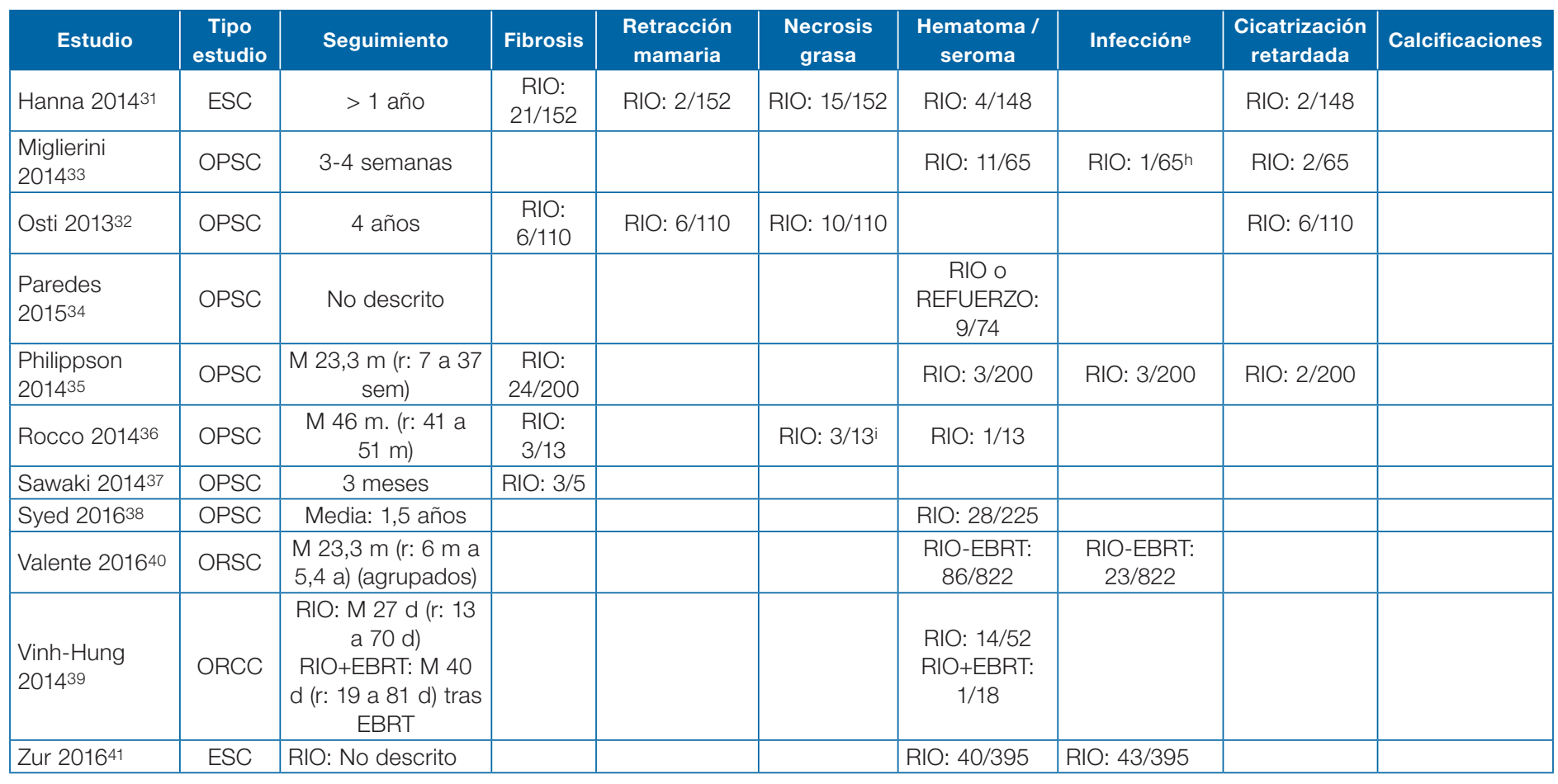

a: años; d: días; ECA: Ensayo Clínico controlado y Aleatorizado; ECC: Experimental Con grupo Control; ESC: Experimental Sin grupo Control; M: Mediana; m: meses; OPCC: Observacional Prospectivo Con grupo Control; OPSC: Observacional Prospectivo Sin grupo Control; ORCC: Observacional Retrospectivo Con grupo Control; ORSC: Observacional Retrospectivo Sin grupo Control; r: rango. Resultados de la tabla en negrita: $\mathrm{P}<0,05$

e: Infección que requiere la administración de tratamiento antibiótico intravenoso o cirugía

f: Crónico, persistente a los 6 meses.

g: Agudo, de aparición en el primer mes que requieren drenaje.

h: Infección de lecho quirúrgico.

i: No se tienen en cuenta los 4 casos de liponecrosis asintomática, identificada mediante mamografía. 
Mediante un estudio observacional retrospectivo, Falco et al. 2016, estiman que añadir EBRT a la RIO incrementa las probabilidades, en el tiempo, de la aparición de seromas, HR= 5,5; (IC95\%: 2,0 a 14,7), que precisan de evacuación más allá de los 6 meses de tratamiento 28 .

En otro estudio retrospectivo y controlado, la aparición de seromas postquirúrgicos y hematomas fueron las complicaciones más frecuentemente observadas (86/822 mujeres) pero, a pesar de contar con 4 grupos de exposición tras la administración de radioterapia (RIO y EBRT solas o combinadas), los autores del estudio muestran los resultados sobre seguridad agrupados, sin que se pueda observar si hubo diferencias entre grupos ${ }^{40}$.

En un estudio experimental con 395 mujeres a las que se les administró RIO, sin grupo control, realizado en Israel, la infección fue el evento observado más frecuente $(10,9 \%)$, seguido de la aparición de seromas $(10,1 \%)$, así como por las dehiscencias de la herida, sangrado y necrosis de la piel (con diámetro máximo de $2 \mathrm{~cm}$ ), $8,1 \%, 2,8 \%$ y $0,5 \%$ respectivamente. No se describe el periodo de seguimiento, aunque sí se ofrece la mediana de los tiempo precisados hasta la recuperación y que ha variado desde los 20 días para las infecciones a los 241 días para la resolución de los seromas, con unos límites superiores en el rango de 539 días y 1.519 días respectivamente ${ }^{41}$.

En una muestra de 110 pacientes a las que se les aplicó RIO y con una mediana de seguimiento de 27 meses (rango: 2 a 54 meses), se observó la aparición de complicaciones descritas en la tabla 2 , además, de edema leve $(1,8 \%)$ acompañado de dolor ocasional $(1,8 \%)$ en la mama irradiada (RIO) en dos mujeres ${ }^{32}$. Otros autores describen la aparición de dolor leve en el pecho intervenido (3/5 mujeres) a los 3 meses. El seguimiento realizado en el estudio es inferior a 12 meses $^{37}$.

Elsberger et al. 2014, describen la aparición de calcificaciones y retracción de la mama en 141 mujeres (ver tabla 2). Así mismo, describen la aparición radiológica de un incremento de la densidad mamaria en mujeres que recibieron EBRT, 25/80 (31,3\%) respecto a las que recibieron RIO, $6 / 61(9,8 \%), p=0,002$, y engrosamiento de la piel tras la administración de EBRT, 26/80 (32,5\%), RIO, 10/61 (16,4\%), p=0,03, con un seguimiento aproximado de 4 años para aquellas mujeres que recibieron EBRT y de 5 años para las que recibieron RIO25.

Otro tipo de incidencias son las cicatrices hipertróficas que, en un estudio experimental (fase I/II) sin grupo control, se observó su aparición tras RIO en 10 de las 32 mujeres intervenidas (análisis por intención de tratar), transcurrido un año desde la intervención. Sin tratamiento alguno, las cicatrices hipertróficas se mantuvieron en 7 de las mujeres a los 3 años de seguimiento ${ }^{42}$. 
Saibene et al. 2014 investigaron la seguridad cardíaca tras la aplicación de RIO en 43 mujeres. 22 pacientes en mama izquierda y 21 en la derecha. Observaron que los niveles plasmáticos de Troponina I cardíaca ultra-sensible y de péptido natriurético tipo $\mathrm{N}$-terminal proB no se modificaban en tres determinaciones temporales distintas: antes de la RIO, a las 6 horas y a los 12 meses, sugiriendo que la RIO no genera lesiones aguda o crónicas en el corazón ${ }^{43}$.

Para observar la seguridad en todo el proceso, es preciso tener en cuenta el correcto posicionamiento del emisor de radiaciones. Hay autores que estiman hasta en un $25 \%$ de los casos un mal posicionamiento del aplicador o la presencia de tumor residual. Plantean, ante este escenario, la realización de un escáner que permita comprobar la adecuada colocación del emisor de radiaciones, así como el tejido circundante a irradiar ${ }^{46}$.

El éxito de la intervención puede depender también de la observación de una distancia adecuada entre el lecho tumoral y la piel, la creación de un lecho tumoral de gran tamaño, la combinación de ambos o la decisión de intervenir un tumor de tamaño inadecuado. Todos estos son factores que pueden mitigarse con un preoperatorio interdisciplinar y el uso de técnicas de imagen prequirúrgicas ${ }^{47}$.

Hay autores que consideran que la exposición a radiaciones ionizantes puede estar ligada a la aparición de segundas neoplasias no mamarias, en general y en órganos adyacentes a los campos irradiados que, aunque muestran un riesgo absoluto pequeño, el incremento de mujeres supervivientes a largo plazo justificaría que las técnicas de radioterapia respeten los tejidos sanos circundantes ${ }^{44}$, y aunque parece que se ponen de manifiesto los beneficios de la radioterapia en el tratamiento del cáncer de mama, las asunciones de los autores y limitaciones metodológicas de la revisión sistemática señalada, podrían estar enviando mensajes poco claros a los clínicos al asociar la aparición de neoplasias pulmonares y de esófago sin haber tenido en cuenta variables como la edad, el consumo habitual de tabaco o la administración de agentes quimioterápicos ${ }^{45}$.

\section{Preferencias de las mujeres}

Un estudio explora entre mujeres candidatas, o que fueron candidatas a cirugía conservadora de mama, las preferencias de elección entre RIO y EBRT (San Francisco - EEUU). Todas las mujeres participaron en una fase introductoria informativa, otra de elección de preferencias según el riesgo de recurrencias de cada alternativa terapéutica y una última de obtención de datos médicos y personales. Analizaron los datos ofrecidos por 81 pacientes. A todas ellas se les solicitó que sopesaran los riesgos y 
beneficios de cada una de las alternativas terapéuticas. 7 mujeres optaron por EBRT aunque esta alternativa presentara mayores riesgos que RIO. 22 aceptaron RIO a igual riesgo de recurrencia que EBRT y 52 eligieron RIO aún con más riesgo de recurrencia que EBRT. La mediana del riesgo adicional de recidiva local aceptable por las mujeres participantes para la alternativa RIO fue del 2,3\% (rango: entre $-9 \%$ y 39\%). De la muestra de mujeres con las que se realizó el estudio, un porcentaje elevado de mujeres con cáncer de mama, aceptó un incremento pequeño del riesgo de recurrencia local con la administración de RIO ${ }^{48}$.

\section{Preferencias de los profesionales de la salud}

En Australia, se investigó en profesionales sanitarios que trabajan con pacientes diagnosticadas de cáncer de mama, qué incremento máximo del riesgo de recurrencia local estaban dispuestos a aceptar para optar por la RIO en lugar de la EBRT, si fueran ellas mismas, las personas que tuvieran que tomar la decisión. A todos los participantes, se les describió la recurrencia local como un evento que no tenía impacto sobre la supervivencia global. El 3,3\% de los encuestados en 2011 respondieron que "nunca" aceptarían la RIO, esta misma respuesta se obtuvo en el 7,5\% de los encuestados en el año 2004 (ver tabla 3).

Tabla 3. Resultados de los cuestionarios remitidos por profesionales sanitarios que trabajan con pacientes con cáncer de mama.

\begin{tabular}{|l|c|c|}
\hline \multicolumn{1}{|c|}{ Cuestionarios } & $\mathbf{2 0 0 4}$ & $\mathbf{2 0 1 1}$ \\
\hline Enviados & $\mathbf{2 0 0}$ & 317 \\
\hline Respuestas & $90(45 \%)$ & $110(35 \%)$ \\
\hline Excluidos & $10(11 \%)$ & $18(16 \%)$ \\
\hline Analizados & $80(89 \%)$ & $92(84 \%)$ \\
\hline \multicolumn{1}{|c|}{ Aceptabilidad de la RIO } & $\mathbf{2 0 0 4}$ & $\mathbf{2 0 1 1}$ \\
\hline Nunca & $6(7,5 \%)$ & $3(3,3 \%)$ \\
\hline Riesgo RIO = EBRT & $14(17,5 \%)$ & $19(20,7 \%)$ \\
\hline $\begin{array}{l}\text { Riesgo Bajo (1\%-3\%) } \\
\text { RIO > EBRT }\end{array}$ & $45(56 \%)$ & $54(59 \%)$ \\
\hline $\begin{array}{l}\text { Riesgo Alto (4\%-6\%) } \\
\text { RIO >> EBRT }\end{array}$ & $15(19 \%)$ & $16(17 \%)$ \\
\hline
\end{tabular}

Extraído de Corica et al. 2014. 
Entre un 55\% y $60 \%$ de los profesionales del estudio de Corica et al. 2014 , que trabajan con pacientes con cáncer de mama, mostraron su disposición a aceptar la RIO asumiendo un mayor riesgo de recidiva local (diferencia absoluta del riesgo de la RIO frente a EBRT entre el 1\% y 3\%

\section{Resultados estéticos}

Dos de los seis estudios seleccionados que comparan RIO con EBRT, obtienen los siguientes resultados estéticos: uno muestra resultados con diferencias estadísticamente significativas ${ }^{53}$ y el otro, al establecer el umbral de significación en $\mathrm{p}=0,01$, ofrece resultados sin significación estadística ${ }^{50}$. Los estudios restantes no ofrecen resultados comparados con un grupo control35,38,51,52(ver tabla 4).

A partir de un subgrupo de mujeres del ensayo TARGIT-A, intervenidas quirúrgicamente y a las que en un segundo tiempo se les aplicó RIO (60 pacientes) tras la reapertura de la herida (grupo post-patología) o se le aplicó EBRT (66 pacientes), se analizaron los resultados estéticos referidos por ellas mismas mediante el Harris Scale Scoring System, que clasifica los resultados en 4 categorías que van de excelente a pobre. Para el análisis e interpretación de los resultados y para tener en cuenta las comparaciones múltiples, definieron un umbral de significación estadística de $\mathrm{p}<0,01$. Sin que se objetivasen diferencias entre el grupo RIO y el grupo EBRT en la primera determinación basal, realizada tras la cirugía y antes del tratamiento radioterápico en ambos grupos, se observaron unos resultados estéticos clasificados como "excelentes-buenos" en cada grupo del $85 \%$ y $82 \%$ respectivamente. Al cabo de 5 años de seguimiento, la muestra de mujeres del estudio clasificó los resultados estéticos como "excelentes-buenos" en el $90 \%$ y $68,4 \%$ respectivamente, sin que las diferencias observadas se hayan considerado estadísticamente significativas por los autores del estudio $(\mathrm{p}=0,042)^{50}$.

Mediante un estudio retrospectivo, se analizaron los resultados estéticos de 78 mujeres intervenidas por cáncer de mama (entre noviembre de 2010 y octubre de 2012) mediante lumpectomía y RIO, lo que supuso un total de 80 intervenciones ( 2 mujeres intervenidas de ambos senos). 66 mujeres $(85 \%)$ no precisaron más intervenciones tras la cirugía y RIO. 12 mujeres (15\%) precisaron de cirugía adicional. Refieren los resultados estéticos mediante la obtención de fotografías y la utilización de la Harvard Cosmesis Scale para su análisis al mes, 6 y 12 meses tras la intervención, contando para ello, con 32, 34 y 17 mujeres respectivamente. Son clasificadas (por 4 evaluadores independientes) con resultados estéticos excelentes o buenos las fotografías del $73 \%$ de las mujeres al mes, $87 \%$ a los 6 meses 
y $92 \%$ al año. El único factor identificado y asociado con un incremento del riesgo que la valoración pase a ser clasificada en las categorías de regular o mala fue añadir EBRT al tratamiento (no muestran estos resultados). No se informa si alguna de las 32 mujeres a las que se evalúan los resultados estéticos formaron parte del grupo de 12 mujeres a las que se realizó una segunda intervención ${ }^{51}$.

Sin grupo de comparación, otro estudio evalúa los resultados estéticos tras la aplicación de RIO. Mediante exámenes clínicos y análisis de fotografías (dos imágenes con vistas frontales y de perfil) y un cuestionario local cumplimentado de forma independiente por la paciente y el médico, se tuvieron en cuenta, la forma y posición del seno, forma de la areola y presencia o ausencia de telangiectasias. A los 2 años del tratamiento, 27/31 $(87,1 \%)$ de las mujeres consideran que los resultados estéticos globales son excelentes o buenos. A los 5 años, el resultado es de un 85,7\% (24/28). Los médicos, valoran con resultados excelentes o buenos, a los dos años, a 29/32 mujeres $(90,6 \%)$ y a $25 / 27$ mujeres $(92,6 \%)$ a los 5 años. La concordancia entre médicos y pacientes (coeficiente kappa) para los resultados estéticos globales fue muy baja, entre 0,09 a los 2 años y 0,04 a los 5 años. La concordancia entre pacientes y médicos aumentó, cuando los ítems de valoración del resultado estético sobre tamaño y forma del pecho se reclasificaron en dos categorías (sin diferencias o pequeñas $v s$. diferencias moderadas o grandes), obteniéndose un kappa de 0,46 y 0,60 a los 2 y 5 años respectivamente en la evaluación del resultado estético del tamaño del seno, o de 0,63 para la forma del pecho, tanto a los 2 como a los 5 años. Partiendo de una muestra de 40 mujeres, los autores no explican los motivos por los que, a lo largo del tiempo de seguimiento, entre 12 y 13 mujeres no son evaluadas, ofreciendo los resultados del análisis por protocolo 52 .

Philippson et al. 2014 realizan un análisis de resultados estéticos valorados por médicos y pacientes sin aportar datos desagregados. Describen, con un mínimo de tiempo transcurrido desde la intervención y RIO de 7 meses, que el 92,5\% (185/200) de las mujeres presentaron resultados estéticos excelentes o buenos ${ }^{35}$. Otro estudio sobre 242 mujeres informa de unos resultados estéticos excelentes o buenos al año, del 95\%, sin que especifiquen quienes realizaron la valoración ${ }^{38}$.

En un estudio experimental con grupo control y sin aleatorización, 143 mujeres fueron intervenidas quirúrgicamente por cáncer de mama. A 72 se les aplicó RIO y a 71 EBRT. Los resultados estéticos fueron evaluados 1 año después de la intervención por cirujanos, cirujanos plásticos y oncólogos radioterapeutas. En el grupo RIO, de las 59 mujeres evaluadas, 53 $(90 \%)$ presentaron resultados excelentes o buenos y en el grupo EBRT, 42 de las 56 mujeres evaluadas (75\%), observándose diferencias estadísticamente significativas $(\mathrm{p}=0,032)$. Análisis realizado por protocolo53. 
Tabla 4. Características de los estudios sobre resultados estéticos

\begin{tabular}{|c|c|c|c|c|c|c|}
\hline Estudio & Mujeres & Escala & $\begin{array}{c}\text { Tiempo } \\
\text { seguimiento }\end{array}$ & Evaluadores & $\begin{array}{l}\text { Desagregan } \\
\text { resultados }\end{array}$ & $\begin{array}{c}\text { Resultados } \\
\text { (excelente + bueno) }\end{array}$ \\
\hline \multirow{2}{*}{ Corica et al. 201650} & $\mathrm{RIOa}: 69$ & \multirow{2}{*}{$\begin{array}{c}\text { Harris Scale } \\
\text { Scoring System }\end{array}$} & \multirow{2}{*}{5 años } & \multirow{2}{*}{-} & \multirow{2}{*}{-} & RIO: 90\% \\
\hline & EBRT: 66 & & & & & EBRT: $68,4 \%$ \\
\hline Grobmyer et al. 201351 & 78 & $\begin{array}{c}\text { Harvard } \\
\text { Cosmesis Scale }\end{array}$ & 1 año & 4 & $\mathrm{NOb}$ & $92 \%$ \\
\hline \multirow{2}{*}{ Lemanski et al. 201352} & 28 mujeres & \multirow{2}{*}{$\begin{array}{c}\text { Imagen (frontal } \\
+ \text { lateral) y } \\
\text { cuestionario }\end{array}$} & \multirow{2}{*}{5 años } & Pacientes & \multirow{2}{*}{ sí } & Pacientes: 85,7\% \\
\hline & 27 mujeres & & & Clínicos & & Clínicos: 92,6\% \\
\hline Philippson et al. 201435 & 200 & Escala estéticac & 7 mesesd & $\begin{array}{l}\text { Pacientes } \\
\text { Clínicos }\end{array}$ & $\mathrm{NOb}$ & $92,5 \%$ \\
\hline Syed et al. 201638 & 242 & - & $\approx 1$ año & - & $\mathrm{NOb}$ & $95 \%$ \\
\hline \multirow{2}{*}{ Zhou et al. 201253} & RIO: 59 & \multirow{2}{*}{ Escala estéticae } & \multirow{2}{*}{1 año } & \multirow{2}{*}{ Clínicos } & \multirow{2}{*}{-} & $\mathrm{RIO}: 90 \%$ \\
\hline & EBRT: 56 & & & & & EBRT: $75 \%(p=0,032)$ \\
\hline
\end{tabular}

a:Intervenidas quirúrgicamente y a las que en un segundo tiempo se les aplicó RIO tras la reapertura de la herida.

b: Tampoco informa del grado de concordancia entre evaluadores.

c: Escala estética descrita por Beal et al. 200758.

d: Es el tiempo mínimo transcurrido desde la intervención.

e: Escala estética descrita por Dubois et al. 199759. 


\section{Calidad de vida percibida por las mujeres}

En el estudio de Corica et al. 2016 se analizó la calidad de vida percibida por 126 mujeres (residentes en la región oeste de Australia) que fueron intervenidas quirúrgicamente y recibieron posteriormente radioterapia, bien mediante la técnica de RIO en un segundo tiempo, bien EBRT. Se empleó el cuestionario European Organization for Research and Treatment of Cancer (EORTC) de calidad de vida (quality of life questionnaire) QLQC30, el módulo Breast-Specific (BR23) y el cuestionario Body Image after Breast Cancer Questionnaire (BIABC). Observaron la significación estadística y clínica o diferencia mínimamente importante (ver glosario). Se estudiaron 8 dominios: imagen corporal, síntomas mamarios, función sexual, satisfacción sexual, preocupación por el brazo, preocupación por el cuerpoa, estigma corporal ${ }^{\mathrm{b}}$ y transparenciac. Las puntuaciones medias obtenidas basalmente (tras cirugía y antes de cualquiera de las modalidades de radioterapia) no mostraron diferencias estadísticamente significativas (para un umbral de significación $\mathrm{p}<0,01$ ), aunque la puntuación de calidad de vida global mostró mejor puntuación en grupo de RIO $(79,5)$ que en el grupo EBRT $(70,3)$ siendo las diferencias, estadísticamente significativas $(\mathrm{p}=0,007)$ d. Posteriormente se reevaluaron estos dominios a los 3, 6, 9 meses y al año, 2, 3, 4 y 5 años. Para los dominios de: imagen corporal, preocupación por el cuerpo, estigma corporal y transparencia no se observaron diferencias, ni estadística ni clínicamentee significativas entre las percepciones de ambos grupos. Se observaron diferencias clínicamente significativas a favor de RIO en el dominio de síntomas mamarios a los 6 meses y al año. Para la función sexual al año, 2, 3, 4 y 5 años, y la satisfacción sexual al año, 2,3 y 4 años y para la preocupación por el brazo, al año50 (ver tabla 5).

\footnotetext{
a. Inquietudes generales con la forma y aspecto general del cuerpo.

b. Sentimientos de vergüenza sobre el cuerpo y la apariencia.

c Preocupación de lo evidente del cáncer para otras personas.

d. A mayor puntuación, mejores resultados.

e. Adoptaron que la significación clínica se alcanzaba al observar una diferencia $>10$ en una escala de 100 puntos.
} 
Tabla 5. Resumen de los resultados con o sin significación estadística y clínica

\begin{tabular}{|c|c|c|c|c|c|c|c|c|c|}
\hline $\begin{array}{l}\text { (estadísticos / } \\
\text { clínicos) }\end{array}$ & Basal & $3 m$ & $6 m$ & $9 \mathrm{~m}$ & 1a & $2 a$ & $3 a$ & $4 a$ & $5 a$ \\
\hline $\begin{array}{l}\text { Imagen } \\
\text { corporal }\end{array}$ & (ns/-) & (ns/-) & (ns/-) & (ns/-) & (ns/-) & (ns/-) & (ns/-) & (ns/-) & (ns/-) \\
\hline $\begin{array}{l}\text { Síntomas } \\
\text { mamarios }\end{array}$ & (ns/-) & (ns/-) & $(\mathbf{s} / \mathbf{s})$ & (s/ns) & $(\mathbf{s} / \mathbf{s})$ & (s/ns) & (s/ns) & (s/ns) & (s/ns) \\
\hline $\begin{array}{l}\text { Función } \\
\text { sexual }\end{array}$ & (ns/-) & (ns/-) & (ns/-) & (ns/-) & $(\mathrm{ns} / \mathrm{s})$ & (ns/s) & (ns/s) & (ns/s) & $(\mathbf{s} / \mathbf{s})$ \\
\hline $\begin{array}{l}\text { Satisfacción } \\
\text { sexual }\end{array}$ & (ns/-) & (ns/-) & (ns/-) & (ns/-) & $(\mathrm{ns} / \mathrm{s})$ & (ns/s) & $(\mathrm{ns} / \mathrm{s})$ & (ns/s) & (ns/-) \\
\hline $\begin{array}{l}\text { Preocupación } \\
\text { por el brazo }\end{array}$ & (ns/-) & $(-/-)$ & (ns/-) & (ns/-) & $(\mathbf{s} / \mathbf{s})$ & (ns/-) & (ns/ns) & (ns/-) & (ns/-) \\
\hline $\begin{array}{l}\text { Preocupación } \\
\text { por el cuerpo }\end{array}$ & (ns/-) & $(-/-)$ & $(-/-)$ & $(-/-)$ & (ns/-) & (ns/-) & (ns/-) & (ns/-) & (ns/-) \\
\hline $\begin{array}{l}\text { Estigma } \\
\text { corporal }\end{array}$ & (ns/-) & $(-/-)$ & $(-/-)$ & $(-/-)$ & (ns/-) & (ns/-) & (ns/-) & (ns/-) & (ns/-) \\
\hline Transparencia & (ns/-) & $(-/-)$ & $(-/-)$ & $(-/-)$ & (ns/-) & (ns/-) & (ns/-) & (ns/-) & (ns/-) \\
\hline
\end{tabular}

s: Significativo $(\mathrm{p}<0,01)$. ns: No significativo; m: mes; a: años

Se destacan en negrita los resultados clínicamente significativos para cada dominio. En todos ellos, con resultados a favor de RIO.

\section{Seguridad del personal sanitario}

El tratado constitutivo de la Comunidad Europea de la Energía Atómica (EURATOM) dispone que, la Comunidad deberá establecer normas uniformes de protección sanitaria de los trabajadores y de la población, contra los riesgos que resulten de las radiaciones ionizantes, dirigidas a señalar las dosis máximas admisibles que sean compatibles con una seguridad adecuada, los niveles de contaminación máximos admisibles y los principios fundamentales de la vigilancia sanitaria de los trabajadores ${ }^{60}$. En España, los límites de dosis efectiva para los trabajadores expuestos a radiaciones ionizantes se sitúa en 50 $m S v$ por año oficial60. En EEUU, el límite se sitúa en los $5000 \mathrm{mR}$ o en torno a los $100 \mathrm{mR}$ por semana, calculados a partir de la siguiente ecuaciónf:

f. La carga de trabajo se calcula como el número de pacientes con RIO que se espera tratar por semana (definido como 5 pacientes). El tiempo máximo de tratamiento por paciente se estima en torno a los 25 minutos, por lo que la exposición máxima no debería exceder los 125 minutos ó 2,1 horas. $1 \mathrm{mR}$ equivale a $0,00877 \mathrm{mSv}$ ó, $1 \mathrm{mSv}=114 \mathrm{mR}$. 
Exposición semanal prevista $=$ tasa de exposición $\mathrm{x}$ carga de trabajo

Un estudio realizado en EEUU evaluó las tasas de exposición a radiaciones ionizantes (rayos $\mathrm{x}$ ) en las inmediaciones de un dispositivo de RIO. Las mediciones las realizaron en una simulación y durante los tratamientos de RIO en tres pacientes con cáncer de mama, suelo de la boca y cuello. El procedimiento que utiliza el balón intraoperatorio para pacientes con cáncer de mama ha demostrado la emisión potencial de altas tasa de radiación. Las determinaciones realizadas durante la intervención de la paciente con cáncer de mama mostraron que la exposición máxima, en el extremo izquierdo de la paciente (neoplasia en mama izquierda), a $60 \mathrm{~cm}$ de distancia, fue de $88 \mathrm{mR} \mathrm{h}^{-1}$, es decir, el equivalente aproximado de un $180 \%$ de la dosis máxima semanal permitida. Tras la protección con delantales plomados, la exposición a $120 \mathrm{~cm}$ pasó a ser de $30 \mu \mathrm{R} \mathrm{h}^{-1} \mathrm{y}$ de $118 \mu \mathrm{R} \mathrm{h} \mathrm{h}^{-1} \mathrm{a} 45 \mathrm{~cm}$ de distancia de la fuente. Los autores concluyen que el dispositivo es adecuado para los quirófanos estándar y que la protección con delantales de plomo debe ser utilizada por todo el personal, dentro de la sala de quirófano y durante la emisión de radiaciones, a una distancia mínima de 1 metro de la mesa de tratamiento ${ }^{54}$.

\section{Evaluación económica de la RIO}

Alvarado et al. 2013 realizan una evaluación económica de la RIO frente a la EBRT desde una perspectiva social. Diseñan un modelo de Markov a 10 años vista con una cohorte de mujeres de 55 años de edad, para evaluar expectativa de vida, años de vida ajustados según la calidad (AVAC) y coste incremental. Asumen un 1,20\% de recidiva local ipsilateral a los 4 años en el grupo RIO y de un 0,95\% en el grupo EBRT, a partir de los datos preliminares del estudio TARGIT-A ${ }^{61}$. Muestran que la RIO es la estrategia dominante y que medido en AVACs, RIO fue también la opción preferida, ofreciendo mayor AVACs y menores costes 56 .

Se identificó un estudio que realiza una evaluación económica de la RIO comparada con seis alternativas de tratamiento radioterápicog (la radiación total de la mama - EBRT y distintas modalidades de radiación acelerada parcial de la mama - APBI) ${ }^{55}$. Los autores del estudio destacan

g.: WBI 3D-CRT: whole-breast irradiation 3-dimensional conformal radiotherapy; APBI 3DCRT: accelerated partial-breast irradiation 3-dimensional conformal radiotherapy; APBI IMRT: accelerated partial-breast irradiation intensity-modulated radiation therapy; APBI ML: accelerated partial-breast irradiation multilumen; APBI SL: accelerated partial-breast irradiation single-lumen; APBI Intersticial: accelerated partial-breast irradiation intersticial. 
que los costes de RIO, cuando se tienen en cuenta exclusivamente los costes de profesionales e instalaciones, es la opción más económica (\$3.094) con respecto al resto de opciones, con un ahorro de costes comprendido entre los $\$ 3.484$ de la APBI 3D-CRT a los $\$ 13.345$ de la APBI ML, sin embargo, y a pesar del menor coste que genera RIO sobre el resto de alternativas, EBRT y el resto de modalidades APBI representan modalidades rentables para administrar radioterapia en base a los análisis de costes por AVAC, al igual que cuando se analiza en base a las RCEI, en el que las alternativas a RIO son coste efectivas, con unos RCEI de la enfermedad comprendidos entre \$244 y \$1.694 por porcentaje de mejora en el control de la enfermedad 55 .

Picot et al. 2015 desarrollan un modelo analítico de decisión para realizar una evaluación económica en términos de costes, beneficios y coste efectividad entre la RIO y la EBRT. La perspectiva del análisis es desde el proveedor y social a 40 años vista. Midieron los resultados en términos de costes ahorrados por AVAC perdido. El grupo de investigadores consideraron que RIO es menos costoso, pero también menos efectivo que la EBRT, dado que se asocia a un coste total menor, y a un menor número de AVACs ganados. El análisis de sensibilidad muestra que la EBRT tiene una mayor probabilidad que la RIO de ser rentable en los umbrales de disposición a pagar entre $£ 20.000$ y $£ 30.000$ por AVAC. El análisis de sensibilidad determinista encuentra cuatro parámetros para los cuales la diferencia entre los valores superiores e inferiores supone un cambio de la opción de tratamiento, que se considera rentable en el umbral de $£ 20,000$ por AVAC. Los parámetros para los que el modelo es más sensible son: la probabilidad de cualquier otra recurrencia asumida para EBRT y para RIO, el coeficiente beta para el tiempo de recurrencia local (RIO) y la probabilidad de muerte por cáncer de mama (RIO)6. 



\section{Discusión}

Entre las ventajas que ofrece la RIO, destaca la reducción de visitas de tratamiento o la posibilidad de blindar órganos circundantes (ver tabla 6), y entre las desventajas, la necesidad de asumir un mayor riesgo de recidiva local que no parece afectar a la mortalidad o la falta de resultados definitivos de anatomía patológica antes de administrar la RIO62.

\section{Tabla 6. Ventajas y desventajas de la RIO62.}

\begin{tabular}{|c|c|}
\hline \multirow[t]{7}{*}{ Ventajas } & $\begin{array}{l}\text { Reducción de las visitas de tratamiento al administrar una única } \\
\text { fracción de radioterapia de inmediato, durante la cirugía de } \\
\text { escisión local amplia. }\end{array}$ \\
\hline & $\begin{array}{l}\text { Radioterapia accesible para pacientes que viven lejos de un centro de } \\
\text { radioterapia. }\end{array}$ \\
\hline & $\begin{array}{l}\text { Sin demora en el tratamiento para pacientes que también deben } \\
\text { someterse a quimioterapia como parte del tratamiento contra el cáncer } \\
\text { de mama. }\end{array}$ \\
\hline & $\begin{array}{l}\text { El lecho quirúrgico se visualiza inmediatamente antes de la } \\
\text { administración del tratamiento de radioterapia. }\end{array}$ \\
\hline & $\begin{array}{l}\text { Se minimiza la probabilidad de perder el objetivo con la oncoplastia } \\
\text { mediante cirugía conservadora de la mama. }\end{array}$ \\
\hline & Blindaje de órganos circundantes realizado. \\
\hline & Posible reducción adicional en los costos de atención médica. \\
\hline \multirow[t]{5}{*}{ Desventajas } & Aumento de los tiempos de operación. \\
\hline & Falta de resultados patológicos finales antes de administrar RIO. \\
\hline & $\begin{array}{l}\text { Aumento de las tasas de recidiva local en comparación con la EBRT } \\
\text { convencional en dos ECA }{ }^{33,34} \text {. }\end{array}$ \\
\hline & Capacitación del personal y esfuerzos de equipos de quirófano. \\
\hline & Dispositivos caros. \\
\hline
\end{tabular}

RIO: Radioterapia IntraOperatoria; EBRT: Radioterapia externa; ECA: Ensayo Clínico Aleatorizado.

\section{Efectividad de la RIO}

En el estudio de Veronesi et al. 2013, las mujeres que recibieron RIO mediante electrones y clasificadas como de alto riesgo para desarrollar 
recurrencias ipsilaterales, mostraron a lo largo del periodo de seguimiento de 5 años, una tasa de recurrencias superior al $10 \% 11$. Se pone de manifiesto la necesidad de seleccionar adecuadamente a las mujeres susceptibles de utilizar RIO en sustitución de EBRT. Esto motiva que haya investigadores que sigan proponiendo la utilización de la RIO de manera controlada, mediante protocolos institucionales ${ }^{63}$, dado que es necesario seguir trabajando también en la identificación de subgrupos de mujeres con cáncer de mama localizado que puedan obtener los mejores beneficios de la aplicación de RIO. Para ello, en el informe de Cantero et al. 2013 se describe con detalle los contenidos a recoger en un protocolo de implantación de un programa de RIO, estructurados en: 1-criterios de aplicación de la RIO, 2-criterios de selección de pacientes, 3-programa de seguimiento de pacientes, 4-definición de la documentación específica del procedimiento y 5 -periodo de formación en centros con experiencia ${ }^{2}$.

Vaidya et al publican un informe de evaluación de tecnologías sanitarias 64 al que trasladan los datos publicados en 201410 y donde describen que calculan la diferencia de proporciones binomiales para expresar los resultados observados a lo largo de 5 años entre RIO y la EBRT y donde informan, tras el análisis que hace el National Institute for Health and Care Excellence (NICE) de su trabajo, que no es adecuado calcular la diferencia de proporciones binomiales para expresar los resultados observados ${ }^{64}$, tal como señalaban otros autores ${ }^{65}$, algunos de los cuales cuestionan incluso el diseño, ejecución y análisis realizado ${ }^{66}$ en el estudio de Vaidya et al. 201410. Según estos autores, la utilización del criterio de no inferioridad es inadecuado, dado que el umbral predeterminado del $2,5 \%$ es superado por el margen superior del intervalo de confianza, que en el trabajo original, fue establecido por los investigadores como intervalo de confianza al $90 \%$. Por otro lado, los cálculos para la prueba de no inferioridad precisan de la información de todos los pacientes a lo largo de 5 años y sólo se dispuso de la información de menos del $20 \%$ de la cohorte66,67. Por otra parte, el trabajo realizado por Vaidya et al. 2014 cuenta con la participación mayoritaria de mujeres postmenopáusicas, tumores grado 1 ó 2 , menores de $2 \mathrm{~cm}$ de tamaño, ganglio negativo, receptor estrogénico positivo, HER2 negativo y tratados con terapia sistémica. De la misma manera, cualquiera de las mujeres asignadas al grupo de RIO con características de alto riesgo recibió también EBRT. Sólo las mujeres de bajo riesgo recibieron exclusivamente RIO, que con los resultados de otros estudios que cifran entre un $4 \%$ y $8 \%$ de recurrencias ipsilaterales a lo largo de un seguimiento de 5 años, se sugiere una irradiación innecesaria de muchas pacientes que podrían haber recibido la cirugía y tratamiento hormonal exclusivamente66.

La edad puede ser un factor no modificable que influya en el resultado de los desenlaces y aunque Abbott et al. 2017 ponen de manifiesto que no existen diferencias entre mujeres de 70 años o más y menores de 70 años 
tras seguimiento comprendido entre medio año y dos años 68 , es deseable contar con estudios que muestren resultados a largo plazo.

En los estudios identificados, hay subgrupos de mujeres a las que se les aplica RIO transcurrido un tiempo, habitualmente tras la realización de un estadiaje más preciso. Este hecho se ha asociado a un incremento de un 4,2\% de las recurrencias ipsilaterales tras la administración de RIO respecto a las mujeres a las que se administró RIO en el acto quirúrgico inicial40.

Según los autores de los estudios analizados, las mujeres con cáncer de mama localizado de bajo riesgo de recurrencia, se beneficiarían, fundamentalmente de la reducción del tiempo de tratamiento con la aplicación de RIO en sustitución de EBRT, asumiendo un mayor riesgo de recidiva local del tumor sin que afecte a otros desenlaces clínicos de interés (mortalidad y aparición de metástasis)10,11. Esto entra en conflicto con lo que afirman otros autores, que sugieren que las mujeres con cáncer de mama que presentan bajo riesgo de recidiva, serían candidatas a cirugía y tratamiento hormonal exclusivamente, obteniendo resultados similares y sin verse expuestas a radiaciones ionizantes y los efectos adversos de las mismas ${ }^{66}$.

\section{Seguridad}

En aquellos estudios con grupo control, la complicación más frecuentemente observada tras la administración de RIO es la necrosis grasa11,23. Otros estudios muestran un mayor número de casos en el grupo de mujeres que recibe RIO, pero no se observan diferencias estadísticamente significativas debidas, fundamentalmente, al reducido tamaño de la muestra de mujeres a estudio ${ }^{26}$.

La técnica de RIO permite la introducción de medidas adicionales de protección de órganos vitales como el corazón que, transcurridos 12 meses no muestra alteraciones bioquímicas a lo largo del tiempo que permitan sospechar la presencia de lesiones agudas o crónica ${ }^{43}$, pero se precisa de estudios que confirmen estos datos de seguridad 69 .

Ofrecer la realización de una técnica de RIO segura y reducir el 25\% de posicionamientos incorrectos del aplicador o de la presencia de tumor residual, requiere contar con un equipo multidisciplinar que disponga de las técnicas de imagen prequirúrgicas adecuadas 47 .

\section{Preferencias de las mujeres}

Los resultados mostrados por Alvarado et al. 2014 sobre preferencias de las mujeres a la hora de elegir entre EBRT y RIO, ponen de manifiesto que el 
$64 \%$ (52/81) de las mujeres de la muestra prefieren la opción de RIO frente a EBRT, incluso asumiendo algo más de riesgo de recidiva local con la administración de la RIO ${ }^{48}$. Así mismo, más del 55\% de los profesionales sanitarios que tratan con pacientes con cáncer de mama, aceptarían la administración de RIO asumiendo un riesgo bajo de recurrencias, aun siendo éste superior a la EBRT49. En el primer caso, los autores del estudio no informan de la procedencia de las mujeres (urbana o rural), ni tampoco del tiempo transcurrido desde la intervención con radioterapia al momento en que se realiza el estudio, y que implica al 74\% (60) de las mujeres de la muestra ${ }^{48}$. En ambos casos, hay un número de personas, no desdeñable, que no están dispuestas a aceptar la RIO si ésta presenta un mayor riesgo de recurrencias locales 48,49 .

\section{Resultados estéticos}

Todos los estudios incluidos que abordan la valoración de resultados estéticos destacan unos resultados excelentes o buenos, sin describir las causas que han podido incidir en los resultados negativos $35,38,50-53$. Se debe destacar también que utilizan diferentes escalas para determinar los resultados estéticos, que los análisis realizados son por protocolo $51-53$ y que para evaluar este desenlace, las pérdidas superan el $20 \%$ de la muestra inicial sin que se describan las causas que han generado las mismas. Destaca el estudio de Grobmyer et al 201351, que con un seguimiento de solo un año y pérdidas del $50 \%$ o superiores, ofrece unos resultados de excelencia o buenos superiores al 90\%, sin ofrecer información alguna que explique las causas de dichas pérdidas y que sin más información, podrían ser atribuidas a malos resultados estéticos. En el caso de aquellos estudios que cuentan con datos de diferentes perfiles de evaluadores, sólo uno de ellos muestra los resultados desagregados y analiza la concordancia entre evaluadores, mostrando una concordancia muy baja (escala ordinal de 4 categorías) que pasa a ser moderada cuando se dicotomizan las categorías del desenlace estudiado52.

\section{Calidad de vida percibida por las mujeres}

El estudio identificado que analiza la calidad de vida de las mujeres, antes y después de la aplicación de RIO50 (en un segundo tiempo tras cirugía), muestra resultados a favor de RIO frente a EBRT, pero hay que tener en cuenta que la calidad de vida percibida antes de la intervención se situaba también a favor, en el grupo al que posteriormente se le administra RIO. Los autores del estudio proponen varias hipótesis para explicar este fenó- 
meno. Por una parte, la posibilidad de que las mujeres asignadas a RIO estuvieran experimentando en ese momento una mejor calidad de vida o el hecho que las mujeres recibieran el cuestionario conociendo de antemano el grupo al que habían sido asignadas, y ello tuviera un efecto positivo en la sensación de bienestar y, por tanto, en la calidad de vida percibida. Las mujeres aleatorizadas a RIO se vieron visiblemente aliviadas por no tener que soportar la carga de 6 semanas de EBRT y, algunas de las pacientes aleatorizadas a EBRT se molestaron al conocer la noticia de ser asignada al brazo convencional, especialmente aquellas mujeres que tendrían que trasladarse a la ciudad durante el tratamiento, dejando personas dependientes, animales $\mathrm{u}$ otras responsabilidades en sus hogares.

\section{Seguridad del personal sanitario}

La exposición a radiaciones ionizantes constituye un riesgo para los profesionales sanitarios responsables de la realización de la técnica de RIO y, se ha puesto de manifiesto que la utilización del balón intraoperatorio para el manejo de las pacientes con cáncer de mama tiene el mayor potencial para la exposición a altas tasas de radiaciones ionizantes, respecto a otras técnicas para cáncer del suelo de boca o bilateral de cuello ${ }^{54}$.

\section{Evaluación económica de la RIO}

Si se tienen en cuenta exclusivamente los costes de profesionales e instalaciones (minimización de costes), la RIO es la opción más económica de entre las alternativas de radioterapia existentes. Esto puede resultar engañoso, dado que, cuando se tienen en cuenta otros costes asociados con RIO (costes médicos adicionales como el incremento de duración de la intervención con RIO, fraccionamiento de la radioterapia en mujeres que precisan radioterapia adicional, u otros costes asociados al exceso de recurrencias y que incluye la mastectomía radical), las alternativas representan modalidades de tratamiento más coste-efectivas ${ }^{55}$. Estos resultados se muestran inconsistentes con los ofrecidos por Alvarado et al. 201356 que describen la RIO como una técnica dominante, que puede estar asociado a la asunción de los datos preliminares ofrecidos por Vaidya et al. 201061 asumiendo un modelo en el que no hay diferencias estadísticamente significativas entre alternativas radioterápicas, cuando las diferencias entre técnicas se ve incrementada en el estudio que, con un mayor seguimiento de las pacientes, es publicado posteriormente ${ }^{10}$. De la misma manera, Picot et al. $2015^{6}$ concluyen que se requeriría una inversión significativa en la capacitación de personal y equipos de RIO para hacer que esta tecnología esté dis- 
ponible para el conjunto del Sistema Nacional de Salud de Reino Unido. Además, y dado el número pequeño de eventos observados en estudios como el de Vaidya et al. 201410, se requiere de una mayor tiempo de seguimiento de las mujeres de este estudio, de la creación de registros y, dados los resultados inciertos de los modelos económicos, proponer modelos económicos futuros que cuenten con datos más robustos. 


\section{Conclusiones}

\section{Técnica estándar}

La opción terapéutica conservadora e inicial del cáncer de mama temprano es la cirugía (lumpectomía) y, si las condiciones permiten la administración de radioterapia, ésta se aplica externamente, irradiando el tejido mamario $\mathrm{y}$, si se considera necesario, el axilar.

\section{Radioterapia intraoperatoria y a quien se dirige}

La radioterapia intraoperatoria (RIO) se presenta como una alternativa sustituta de la radioterapia externa (EBRT) en mujeres con tumores de mama en estadios iniciales y de bajo riego de recurrencias (mujeres con tumores de $2 \mathrm{~cm}$ o menos, menos de 4 ganglios linfáticos positivos, tumores diferenciados, receptor estrogénico positivo y tumor de mama triple positivo).

Con las pruebas actuales, existen dudas razonables de si la lumpectomía más quimioterapia adyuvante constituye o no una alternativa terapéutica para mujeres con estas características. Su indicación implica asumir también un incremento del riesgo de recidiva locoregional y los efectos adversos de la quimioterapia, a la vez que se evita la irradiación de tejidos y sus efectos no deseados.

\section{Eficacia / efectividad de la RIO frente a la EBRT}

En mujeres con cáncer de mama en estadios iniciales, transcurridos 5 años de la intervención, la RIO muestra mayor tasa de recurrencias que la EBRT de manera estadísticamente significativas, a partir de los resultados de los estudios individuales, aunque desde una perspectiva analítica de no inferioridad, la RIO se muestra equivalente a la EBRT. Al metaanalizar los datos, las tasas de recurrencias dejan de ser estadísticamente significativas.

En mujeres con cáncer de mama en estadios iniciales, al comparar la RIO con la EBRT, no se observan diferencias estadísticamente significativas en términos de mortalidad ni aparición de metástasis. 


\section{Seguridad}

La aparición de eventos adversos sobre la piel de la mama (eritema, sequedad, hiperpigmentación, prurito) son más frecuentes con el uso de EBRT. No se observan diferencias en la aparición de fibrosis, retracción de la mama, ni dolor o sensación de quemazón.

El uso de la RIO muestra una mayor incidencia de eventos de necrosis grasa y de aparición de hematomas / seromas que requieren de drenaje.

\section{Preferencias a cerca de la RIO}

Frente a la alternativa de la EBRT:

Más del 50\% de mujeres de una muestra de EEUU candidatas a cirugía conservadora mostraron su preferencia por la opción de RIO, aceptando con ello un incremento pequeño $(2,3 \%)$ del riesgo de recurrencia de la enfermedad.

Más del $50 \%$ de los profesionales sanitarios encuestados en Australia e implicados en el manejo del cáncer de mama, mostraron su preferencia por RIO, asumiendo un mayor riesgo de recidiva comprendido entre el 1 y $3 \%$.

\section{Estética}

Los resultados estéticos alcanzados son excelentes o buenos en el $90 \%$ o más de las mujeres intervenidas con RIO. Esta cifra es inferior si los resultados estéticos son informados por las propias mujeres. Tras la EBRT, en el mejor de los casos, se alcanza unos resultados excelentes o buenos en el $75 \%$ de los casos.

\section{Satisfacción e impacto en la calidad de vida}

$\mathrm{Al}$ analizar las percepciones sobre la imagen corporal, preocupación por el cuerpo, estigma corporal y transparencia, no se observan diferencias ni estadística ni clínicamente significativas.

Los síntomas mamarios fueron menos marcados en las mujeres tras la aplicación de RIO a 5 años vista (diferencias estadísticamente significativas). Las diferencias clínicas a favor de la RIO se pierden a partir del año tras la intervención. 
Tanto la función como la satisfacción sexual muestran mejores resultados tras RIO.

\section{Información a la mujer}

En los centros sanitarios en los que se esté ofreciendo la técnica de RIO a mujeres con diagnóstico de cáncer de mama localizado, en sustitución de la EBRT, la RIO se debe ofrecer bajo protocolos institucionales, con una implementación efectiva, que definan los criterios de aplicación de la RIO, los criterios de selección de pacientes, el plan de seguimiento de estas pacientes, la documentación necesaria para cada etapa y el periodo de formación que precisan los profesionales sanitarios. El objetivo es recabar información de la técnica a largo plazo, con reevaluaciones periódicas, que permitan dilucidar si las mujeres clasificadas actualmente como de bajo riesgo de recidiva son las más beneficiadas frente a otras alternativas como la terapia quimioterápica adyuvante, la EBRT, o si se identifican mujeres con nuevas características que puedan obtener un beneficio óptimo tras la indicación y uso de la técnica.

En los centros que ofrecen actualmente la técnica, debe asegurarse la participación activa de la mujer en la toma de decisiones, en la que se informe:

- Del riesgo de recurrencias del tumor tras la aplicación de la RIO $\mathrm{y}$ tras el tratamiento alternativo (EBRT).

- De la seguridad de RIO y de su alternativa.

- Sobre las ventajas que aporta RIO en cuanto a la protección de órganos vitales como el corazón y las limitaciones que pueden derivarse de un mal posicionamiento del aplicador de radiaciones y la persistencia de tumor residual.

- Sobre resultados estéticos, destacando que pueden estar sobrevalorados por no ser, en general, las propias pacientes quienes han informado de los mismos.

- A cerca de las experiencias previas de mujeres sobre la percepción de la imagen corporal, las preocupaciones por su cuerpo, el estigma corporal y transparencia.

- De la función y satisfacción sexual que puede verse modificada según la técnica utilizada.

Es recomendable que los recursos para informar a la paciente sean variados, incluyendo herramientas gráficas que faciliten la comprensión de conceptos. 


\section{La RIO en un segundo tiempo}

Los centros que ofrecen la técnica de RIO deben implementar medidas encaminadas a realizar una clasificación precisa del estadio tumoral, con el fin de evitar la administración de RIO en un segundo tiempo, dados los indicios de un mayor riesgo de recurrencia ipsilateral asociado y sustituyendo esta opción por la alternativa estándar.

\section{Seguridad de los profesionales sanitarios}

Con la aplicación de la técnica de RIO, tanto los profesionales sanitarios que permanezcan en la sala de quirófano, como aquellos que deben situarse en las inmediaciones de la paciente, tienen que adoptar las medidas de protección frente a radiaciones ionizantes, manteniendo la mayor distancia posible al foco emisor de radiaciones y el uso de delantales plomados en quirófano.

\section{Evaluación económica}

La eficiencia de RIO es controvertida, encontrándose heterogeneidad entre los estudios identificados.

\section{Futuras líneas de investigación}

Las investigaciones futuras sobre evaluación económica de la RIO deben desarrollar modelos que tengan en cuenta los costes asociados al manejo de las recurrencias, la toxicidad y el coste adicional que supone la existencia no detectada previamente de ganglios positivos, en mujeres con cáncer de mama localizado a partir de modelos con una mayor casuística que reduzca la incertidumbre actual. 


\section{Anexos}

\section{Anexo 1. Perfil de evidencia. RIO vs. EBRT}

\section{RIO comparado con EBRT en cáncer de mama}

\begin{tabular}{|c|c|c|c|c|c|}
\hline & \multicolumn{3}{|c|}{ Bilbiografía: Vaidya 2014 y Veronesi $201 ?$} \\
\hline \multirow[b]{2}{*}{ Desenlaces } & \multirow{2}{*}{$\begin{array}{c}\mathrm{N}^{\circ} \text { de } \\
\text { participantes } \\
\text { (estudios) } \\
\text { Seguimiento - } \\
\text { mediana }\end{array}$} & \multirow[b]{2}{*}{$\begin{array}{l}\text { Certainty of the } \\
\text { evidence } \\
\text { (GRADE) }\end{array}$} & \multirow[b]{2}{*}{$\begin{array}{l}\text { Efecto } \\
\text { relativo } \\
(95 \% \mathrm{CI})\end{array}$} & \multicolumn{2}{|c|}{$\begin{array}{l}\text { Efectos absolutos } \\
\text { anticipados }\end{array}$} \\
\hline & & & & $\begin{array}{l}\text { Riesgo } \\
\text { con } \\
\text { EBRT }\end{array}$ & $\begin{array}{c}\text { La } \\
\text { diferencia } \\
\text { de riesgo } \\
\text { con RIO }\end{array}$ \\
\hline Recurrencias & $\begin{array}{l}4680 \\
(2 \text { [ECAs]) } \\
5 \text { años }\end{array}$ & $\begin{array}{l}\oplus \oplus \circ \bigcirc \\
\text { BAJAa }\end{array}$ & $\begin{array}{l}\text { RR 4,11 } \\
(0,99 \mathrm{a} \\
17,13)\end{array}$ & $\begin{array}{l}6 \text { por } \\
1.000\end{array}$ & $\begin{array}{l}20 \text { más } \\
\text { por } \mathbf{1 . 0 0 0} \\
(0 \text { menos a } \\
103 \text { más) }\end{array}$ \\
\hline Metástasis & $\begin{array}{l}4680 \\
\text { (2 [ECAs]) } \\
5 \text { años }\end{array}$ & $\begin{array}{l}\oplus \oplus \oplus O \\
\text { MODERADOb }\end{array}$ & $\begin{array}{l}\text { RR 1,10 } \\
(0,81 \mathrm{a} \\
1,51)\end{array}$ & $\begin{array}{l}31 \text { por } \\
1.000\end{array}$ & $\begin{array}{l}3 \text { más } \\
\text { por } \mathbf{1 . 0 0 0} \\
\text { (6 menos } \\
\text { a } 16 \text { más) }\end{array}$ \\
\hline $\begin{array}{l}\text { Mortalidad } \\
\text { global }\end{array}$ & $\begin{array}{l}4756 \\
(2 \text { [ECAs]) }\end{array}$ & $\begin{array}{l}\oplus \oplus \oplus \oplus \\
\text { ALTAC }\end{array}$ & $\begin{array}{l}\text { RR 0,86 } \\
(0,61 \mathrm{a} \\
1,20)\end{array}$ & $\begin{array}{l}35 \text { por } \\
1.000\end{array}$ & $\begin{array}{l}\mathbf{5} \text { menos } \\
\text { por } \mathbf{1 . 0 0 0} \\
\text { (14 menos } \\
\text { a } 7 \text { más) }\end{array}$ \\
\hline $\begin{array}{l}\text { Mortalidad por } \\
\text { otras causas }\end{array}$ & $\begin{array}{l}4756 \\
(2 \text { [ECAs]) }\end{array}$ & $\begin{array}{l}\oplus \oplus \oplus \oplus \\
\text { ALTAC }\end{array}$ & $\begin{array}{l}\text { RR 0,66 } \\
(0,33 \mathrm{a} \\
1,32)\end{array}$ & $\begin{array}{l}19 \text { por } \\
1.000\end{array}$ & $\begin{array}{l}7 \text { menos } \\
\text { por } \mathbf{1 . 0 0 0} \\
\text { (13 menos } \\
\text { a } 6 \text { más) }\end{array}$ \\
\hline $\begin{array}{l}\text { Mortalidad } \\
\text { por cáncer de } \\
\text { mama }\end{array}$ & $\begin{array}{l}4756 \\
(2 \text { [ECAs]) }\end{array}$ & $\begin{array}{l}\oplus \oplus \oplus \oplus \\
\text { ALTAC }\end{array}$ & $\begin{array}{l}\text { RR 1,20 } \\
(0,77 \text { a } \\
1,86)\end{array}$ & $\begin{array}{l}15 \text { por } \\
1.000\end{array}$ & $\begin{array}{l}3 \text { más } \\
\text { por } \mathbf{1 . 0 0 0} \\
\text { (3 menos } \\
\text { a } 13 \text { más) }\end{array}$ \\
\hline \multicolumn{6}{|c|}{$\begin{array}{l}\text { El riesgo en el grupo de intervención (y su intervalo de confianza del 95\%) se basa en } \\
\text { el riesgo asumido en el grupo de comparación y en el efecto relativo de la intervención (y } \\
\text { su intervalo de confianza del 95\%). } \\
\text { ECAs: Ensayos clínicos controlados y aleatorizados; Cl: Intervalo de confianza; RR: Razón } \\
\text { de riesgo. }\end{array}$} \\
\hline \multicolumn{6}{|c|}{$\begin{array}{l}\text { Grados de evidencia del grupo de trabajo GRADE } \\
\text { Certeza alta: El panel tiene mucha confianza en que el efecto real se aproxima a la estimación } \\
\text { del efecto. } \\
\text { Certeza moderada: El panel tiene una confianza moderada: es probable que el efecto } \\
\text { real se aproxime a la estimación del efecto, pero existe la posibilidad de que sea } \\
\text { considerablemente diferente. } \\
\text { Certeza baja: La confianza del panel en la estimación del efecto es reducida: el efecto real } \\
\text { puede ser considerablemente diferente a la estimación del efecto. } \\
\text { Certeza muy baja: El panel tiene muy poca confianza en la estimación del efecto: es } \\
\text { probable que el efecto real sea considerablemente diferente a la estimación. }\end{array}$} \\
\hline
\end{tabular}




\section{Explicaciones}

a. Coordinadores, investigadores y pacientes no están cegados y los investigadores, que han recogido los datos, se encargan también del análisis e interpretación de los resultados. El análisis realizado por Vaidya et al. 2014, para las recurrencias a 5 años (cálculo de las diferencias de proporciones binomiales), presenta serias limitaciones. La persona con un seguimiento de un mes o de 5 años contribuye de la misma manera en el denominador. Análisis de supervivencia permite conocer toda la información disponible de pacientes, explicar el seguimiento y la aparición de eventos a través del tiempo. Las pacientes fueron censurados cuando fueron vistos por última vez o retirados del ensayo, NO ES POSIBLE conocer si la mujer sin evento en el último contacto ha desarrollado una recurrencia posteriormente. En Veronesi et al. 2013, las recurrencias no alcanzan el margen establecido del 7,5\% (estudios de equivalencia) pero hay diferencias estadísticamente significativas entre intervenciones.

b. Riesgo de sesgo elevado, dado que no hubo enmascaramiento para los participantes en el estudio ni el personal del mismo. Tampoco se realizó una evaluación de resultados cegada.

c. A pesar del riesgo de sesgo elevado por ausencia de enmascaramiento tanto a la asignación a grupos como para los evaluadores, se considera que los desenlaces mortalidad no se ven influenciados por estas limitaciones ${ }^{14}$. 


\section{Anexo 2. Estudios incluidos}

\begin{tabular}{|c|c|}
\hline Artículo & Abordaje \\
\hline Alvarado et al. 201356 & Evaluación económica \\
\hline Alvarado et al. 201448 & Preferencias de las mujeres \\
\hline Corica et al. 201449 & Preferencias de profesionales sanitarios \\
\hline Corica et al. 201650 & Resultados estéticos y calidad de vida \\
\hline Cracco et al. $2015^{23}$ & Seguridad \\
\hline Ebner et al. 201624 & Seguridad \\
\hline Elsberger et al. 201425 & Seguridad \\
\hline Engel et al. 201326 & Seguridad \\
\hline Epstein et al. 201627 & Seguridad \\
\hline Falco et al. 201628 & Seguridad \\
\hline Fernández et al. 201629 & Seguridad \\
\hline Grantzau et al. 201544 & Seguridad \\
\hline Grobmyer et al. 201351 & Resultados estéticos \\
\hline Günay et al. 201630 & Seguridad \\
\hline Hanna et al. 201431 & Seguridad \\
\hline Kawamura et al. 201542 & Seguridad \\
\hline Lemanski et al. 201352 & Resultados estéticos \\
\hline Mallick et al. 201545 & Neoplasias secundarias \\
\hline Miglierini et al. 201433 & Seguridad \\
\hline Mobit et al. $2015^{54}$ & Seguridad profesionales sanitarios \\
\hline Osti et al. $2013^{32}$ & Seguridad \\
\hline Paredes et al. $2015^{34}$ & Seguridad \\
\hline Philippson et al. 201435 & Resultados estéticos \\
\hline Picot et al. $2015^{6}$ & Evaluación económica \\
\hline Rocco et al. 201436 & Seguridad \\
\hline Saibene et al. 201443 & Seguridad \\
\hline Sawaki et al. 201437 & Seguridad \\
\hline Shah et al. 2014b55 & Evaluación económica \\
\hline
\end{tabular}




\begin{tabular}{|l|l|}
\multicolumn{1}{|c|}{ Artículo } & \multicolumn{1}{c|}{ Abordaje } \\
\hline Syed et al. 201638 & Resultados estéticos \\
\hline Trifiletti et al. $2015 \mathrm{a}^{46}$ & Seguridad \\
\hline Tuschy et al. $2013 \mathrm{~b}^{47}$ & Seguridad \\
\hline Vaidya et al. 201410 & Eficacia/efectividad y seguridad \\
\hline Valente et al. $2016^{40}$ & Seguridad \\
\hline Veronesi et al. $2013^{11}$ & Eficacia/efectividad y seguridad \\
\hline Vinh-Hung et al. 201439 & Seguridad \\
\hline Zhou et al. 201253 & Resultados estéticos \\
\hline Zur et al. $2016^{41}$ & Seguridad \\
\hline
\end{tabular}




\section{Anexo 3. Estudios excluidos}

\begin{tabular}{|c|c|}
\hline Artículo & Motivo de EXCLUSIÓN \\
\hline Abbot et al. 201570 & $\begin{array}{l}\text { Objeto del estudio sin interés para la } \\
\text { pregunta de investigación. }\end{array}$ \\
\hline Almeida et al. 201571 & Evidencia analizada individualmente \\
\hline Arsenali et al. $2015^{72}$ & $\begin{array}{l}\text { Intervención sin interés para la pregunta de } \\
\text { investigación }\end{array}$ \\
\hline Baghani et al. 201573 & $\begin{array}{l}\text { Intervención sin interés para la pregunta de } \\
\text { investigación }\end{array}$ \\
\hline Barros et al. $2014^{74}$ & $\begin{array}{l}\text { Intervención sin interés para la pregunta de } \\
\text { investigación }\end{array}$ \\
\hline Barry et al. 201375 & Revisión narrativa \\
\hline Bouzid et al. 201576 & $\begin{array}{l}\text { Intervención sin interés para la pregunta de } \\
\text { investigación }\end{array}$ \\
\hline Bromberg et al. 201377 & $\begin{array}{l}\text { Intervención sin interés para la pregunta de } \\
\text { investigación }\end{array}$ \\
\hline Budrukkar et al. 201578 & $\begin{array}{l}\text { Intervención sin interés para la pregunta de } \\
\text { investigación }\end{array}$ \\
\hline Calvo et al. 201379 & $\begin{array}{l}\text { Objeto del estudio sin interés para la } \\
\text { pregunta de investigación. }\end{array}$ \\
\hline Cantero et al. 20132 & Evidencia analizada individualmente \\
\hline Cedolini et al. 201480 & $\begin{array}{l}\text { Población sin interés para la pregunta de } \\
\text { investigación }\end{array}$ \\
\hline Coombs et al. 201681 & $\begin{array}{l}\text { Desenlaces sin interés para la pregunta de } \\
\text { investigación }\end{array}$ \\
\hline Cox et al. 201382 & Revisión narrativa \\
\hline Eaton et al. 201383 & $\begin{array}{l}\text { Intervención sin interés para la pregunta de } \\
\text { investigación }\end{array}$ \\
\hline Eaton. 201584 & Revisión narrativa \\
\hline Esposito et al. 201562 & Revisión narrativa \\
\hline Esposito et al. 201685 & Revisión narrativa \\
\hline Esserman et al. 201486 & $\begin{array}{l}\text { Intervención sin interés para la pregunta de } \\
\text { investigación }\end{array}$ \\
\hline Fastner et al. 201387 & $\begin{array}{l}\text { Intervención sin interés para la pregunta de } \\
\text { investigación }\end{array}$ \\
\hline Fastner et al. 201588 & $\begin{array}{l}\text { Intervención sin interés para la pregunta de } \\
\text { investigación }\end{array}$ \\
\hline Fastner et al. 201689 & $\begin{array}{l}\text { Intervención sin interés para la pregunta de } \\
\text { investigación }\end{array}$ \\
\hline
\end{tabular}




\begin{tabular}{|c|c|}
\hline Artículo & Motivo de EXCLUSIÓN \\
\hline Goble et al. 201490 & $\begin{array}{l}\text { Intervención sin interés para la pregunta de } \\
\text { investigación }\end{array}$ \\
\hline Goggin et al. 201691 & $\begin{array}{l}\text { Intervención sin interés para la pregunta de } \\
\text { investigación }\end{array}$ \\
\hline Hanna et al. 201592 & Revisión narrativa \\
\hline Hickey et al. $2016 a^{93}$ & Evidencia analizada individualmente \\
\hline Hickey et al. 2016b94 & $\begin{array}{l}\text { Intervención sin interés para la pregunta de } \\
\text { investigación }\end{array}$ \\
\hline Horst et al. 201495 & $\begin{array}{l}\text { Intervención sin interés para la pregunta de } \\
\text { investigación }\end{array}$ \\
\hline IA2010-0196 & Evidencia analizada individualmente \\
\hline Jalaguier et al. 201597 & $\begin{array}{l}\text { Población sin interés para la pregunta de } \\
\text { investigación }\end{array}$ \\
\hline Jones et al. 201498 & $\begin{array}{l}\text { Intervención sin interés para la pregunta de } \\
\text { investigación }\end{array}$ \\
\hline Kalakota et al. 201499 & Revisión narrativa \\
\hline Khan et al. 2013100 & $\begin{array}{l}\text { Intervención sin interés para la pregunta de } \\
\text { investigación }\end{array}$ \\
\hline Khan et al. 2016101 & Revisión narrativa \\
\hline Krengli et al. 2014102 & $\begin{array}{l}\text { Objeto del estudio sin interés para la } \\
\text { pregunta de investigación. }\end{array}$ \\
\hline Kunkler et al. 2014103 & Revisión narrativa \\
\hline Kuzba et al. 2015104 & Revisión narrativa \\
\hline Lehman et al. 2014105 & $\begin{array}{l}\text { Intervención sin interés para la pregunta de } \\
\text { investigación }\end{array}$ \\
\hline Lemanski 2016106 & Revisión narrativa \\
\hline Leonardi et al. 2013107 & $\begin{array}{l}\text { Intervención sin interés para la pregunta de } \\
\text { investigación }\end{array}$ \\
\hline Liu et al. 2013108 & $\begin{array}{l}\text { Intervención sin interés para la pregunta de } \\
\text { investigación }\end{array}$ \\
\hline Livi et al. 2015109 & $\begin{array}{l}\text { Intervención sin interés para la pregunta de } \\
\text { investigación }\end{array}$ \\
\hline López-Tarjuelo et al. 2016a110 & $\begin{array}{l}\text { Intervención sin interés para la pregunta de } \\
\text { investigación }\end{array}$ \\
\hline López-Tarjuelo et al. 2016b111 & $\begin{array}{l}\text { Intervención sin interés para la pregunta de } \\
\text { investigación }\end{array}$ \\
\hline Malter et al. 2014112 & $\begin{array}{l}\text { Intervención sin interés para la pregunta de } \\
\text { investigación }\end{array}$ \\
\hline Maluta et al. 2014113 & Revisión narrativa \\
\hline
\end{tabular}




\begin{tabular}{|c|c|}
\hline Artículo & Motivo de EXCLUSIÓN \\
\hline Marta et al. $2015^{114}$ & $\begin{array}{l}\text { Intervención sin interés para la pregunta de } \\
\text { investigación }\end{array}$ \\
\hline Massarut et al. 2015115 & Revisión narrativa \\
\hline Meattini et al. 2015116 & $\begin{array}{l}\text { Intervención sin interés para la pregunta de } \\
\text { investigación }\end{array}$ \\
\hline Merdad et al. 2013117 & $\begin{array}{l}\text { Intervención sin interés para la pregunta de } \\
\text { investigación }\end{array}$ \\
\hline Murawa et al. 2014118 & Revisión narrativa \\
\hline Orecchia et al. 2014119 & Revisión narrativa \\
\hline Pan et al. 2014120 & $\begin{array}{l}\text { Intervención sin interés para la pregunta de } \\
\text { investigación }\end{array}$ \\
\hline Piroth et al. 2014121 & Revisión narrativa \\
\hline Riet at al. 2014122 & Evidencia analizada individualmente \\
\hline Rivera et al. 2016123 & $\begin{array}{l}\text { Intervención sin interés para la pregunta de } \\
\text { investigación }\end{array}$ \\
\hline Rodríguez-Spiteri et al. 2013124 & $\begin{array}{l}\text { Intervención sin interés para la pregunta de } \\
\text { investigación }\end{array}$ \\
\hline Schaverien et al. 2013125 & $\begin{array}{l}\text { Intervención sin interés para la pregunta de } \\
\text { investigación }\end{array}$ \\
\hline Sedlmayer et al. 2014126 & Revisión narrativa \\
\hline Severgnini et al. 2015127 & $\begin{array}{l}\text { Intervención sin interés para la pregunta de } \\
\text { investigación }\end{array}$ \\
\hline Shah et al. 2014a69 & $\begin{array}{l}\text { Intervención sin interés para la pregunta de } \\
\text { investigación }\end{array}$ \\
\hline Shokrani et al. 2013128 & $\begin{array}{l}\text { Intervención sin interés para la pregunta de } \\
\text { investigación }\end{array}$ \\
\hline Silverstein et al. 2014a63 & $\begin{array}{l}\text { Intervención sin interés para la pregunta de } \\
\text { investigación }\end{array}$ \\
\hline Silverstein et al. 2014b129 & $\begin{array}{l}\text { Intervención sin interés para la pregunta de } \\
\text { investigación }\end{array}$ \\
\hline Spano et al. 2015130 & Revisión narrativa \\
\hline Sperk et al. 20149 & $\begin{array}{l}\text { Intervención sin interés para la pregunta de } \\
\text { investigación }\end{array}$ \\
\hline Strnad et al. 2016131 & $\begin{array}{l}\text { Intervención sin interés para la pregunta de } \\
\text { investigación }\end{array}$ \\
\hline Tejera et al. 2015132 & Revisión narrativa \\
\hline Thompson et al. 2015133 & $\begin{array}{l}\text { Intervención sin interés para la pregunta de } \\
\text { investigación }\end{array}$ \\
\hline Tian et al. 2016134 & $\begin{array}{l}\text { Intervención sin interés para la pregunta de } \\
\text { investigación }\end{array}$ \\
\hline
\end{tabular}




\begin{tabular}{|c|c|}
\hline Artículo & Motivo de EXCLUSIÓN \\
\hline Trifiletti et al. $2015 b^{135}$ & Revisión narrativa \\
\hline Tuschy et al. $2013 \mathrm{a}^{136}$ & $\begin{array}{l}\text { Intervención sin interés para la pregunta de } \\
\text { investigación }\end{array}$ \\
\hline Tuschy et al. $2013 c^{137}$ & $\begin{array}{l}\text { Intervención sin interés para la pregunta de } \\
\text { investigación }\end{array}$ \\
\hline Vaidya et al. 201061 & Evidencia analizada individualmente \\
\hline Vaidya et al. 201664 & Evidencia analizada individualmente \\
\hline Valdivieso et al. 2014138 & $\begin{array}{l}\text { Intervención sin interés para la pregunta de } \\
\text { investigación }\end{array}$ \\
\hline VanderWalde et al. 2013139 & $\begin{array}{l}\text { Intervención sin interés para la pregunta de } \\
\text { investigación }\end{array}$ \\
\hline Vanoni et al. 2014140 & Evidencia analizada individualmente \\
\hline Veronesi et al. 2016141 & Revisión narrativa \\
\hline Wang et al. $2015^{142}$ & $\begin{array}{l}\text { Desenlaces sin interés para la pregunta de } \\
\text { investigación }\end{array}$ \\
\hline Wang et al. 2016143 & $\begin{array}{l}\text { Intervención sin interés para la pregunta de } \\
\text { investigación }\end{array}$ \\
\hline Warenczak et al. $2013^{144}$ & $\begin{array}{l}\text { Intervención sin interés para la pregunta de } \\
\text { investigación }\end{array}$ \\
\hline Welzel et al. 2013145 & Evidencia analizada individualmente \\
\hline Wong et al. 2014146 & $\begin{array}{l}\text { Intervención sin interés para la pregunta de } \\
\text { investigación }\end{array}$ \\
\hline Woolf et al. 2014147 & $\begin{array}{l}\text { Intervención sin interés para la pregunta de } \\
\text { investigación }\end{array}$ \\
\hline Yu et al. 2015148 & $\begin{array}{l}\text { Intervención sin interés para la pregunta de } \\
\text { investigación }\end{array}$ \\
\hline Zhang et al. 201557 & Evidencia analizada individualmente \\
\hline Zioueche et al. 2014149 & $\begin{array}{l}\text { Intervención sin interés para la pregunta de } \\
\text { investigación }\end{array}$ \\
\hline
\end{tabular}




\title{
Anexo 4. Estrategias de búsqueda
}

\section{Pubmed}

\author{
\#1 “Breast Neoplasms”[Mesh] \\ \#2 breast AND (cancer*[tw] OR tumor*[tw] OR tumour*[tw] OR \\ carcinom*[tw] OR neoplas*[tw]) \\ \#3 (\#1 OR \#2) \\ \#4 intraoperative[tw] AND radiation[tw] AND therap*[tw] \\ \#5 IORT[tw] OR IOERT[tw] OR IOEBRT[tw] \\ \#6 intraoperative[tw] AND radiotherap*[tw] \\ \#7 (\#4 OR \#5 OR \#6) \\ \#8 (\#3 AND \#7)
}

\section{Embase}

\#1 ' breast tumor'/exp

\#2 ('breast'/exp OR breast:ab,ti) AND (cancer*:ab,ti OR tumor*:ab,ti OR tumour*:ab,ti OR carcinom*:ab,ti OR neoplas*:ab,ti)

\#3 (\#1 OR \#2)

\#4 intraoperative:ab,ti AND ('radiation'/exp OR radiation:ab,ti) AND therap*:ab,ti

\#5 iort:ab,ti OR ioert:ab,ti OR ioebrt:ab,ti

\#6 intraoperative:ab,ti AND radiotherap*:ab,ti

\#7 (\#4 OR \#5 OR \#6)

\#8 (\#3 AND \#7)

\section{Cochrane}

\#1 MeSH descriptor: [Breast Neoplasms] explode all trees

\#2 breast and (cancer* or tumor* or tumour* or carcinom* or neoplas*):ti,ab,kw (Word variations have been searched) 
\#3 \#1 or \#2

\#4 intraoperative and radiation and therap*:ti,ab,kw (Word variations have been searched)

\#5 intraoperative and radiotherap*:ti,ab,kw (Word variations have been searched)

\#6 IORT or IOERT or IOEBRT:ti,ab,kw (Word variations have been searched)

\#7 \#4 or \#5 or \#6

\#8 \#3 and \#7 Publication Year from 2013

\section{CRD databases}

\#1 (breast AND (cancer* OR tumor* OR tumour* OR carcinom*

OR neoplas*)) IN 2013

\#2 (intraoperative AND radiation AND therap*) IN 2013

\#3 (IORT OR IOERT OR IOEBRT) IN 2013

\#4 (intraoperative AND radiotherap*) IN 2013

\#5 (\#1 AND (\#2 OR \#3 OR \#4))

\section{ISI Web of knowledge}

\#1 TS=(breast) OR TI=(breast)

\#2 TI=(cancer* OR tumor* OR tumour* OR carcinom* OR neoplas*) OR TS=(cancer* OR tumor* OR tumour* OR carcinom* OR neoplas*)

\#3 TS=("intraoperative radiation therapy") OR TI=("intraoperative radiation therapy")

\#4 TS=(IORT OR IOERT OR IOEBRT) OR TI=(IORT OR IOERT OR IOEBRT)

\#5 TS=(intraoperative AND radiotherap*) OR TI=(intraoperative AND radiotherap*)

\#6 (\#1 AND \#2 AND (\#3 OR \#4 OR \#5)) 
IME

\#1 Parámetros: JUNT="'mama"

\#2 Parámetros: JUNT="radioterapia intraoperatoria"

\#3 Parámetros: JUNT="terapia radiación"

\#4 (\#1 AND (\#2 OR \#3))

Clinical Trials:

((breast AND (cancer* OR tumor* OR tumour* OR carcinoma OR neoplasm))) AND ((intraoperative AND radiation AND therapy) OR (intraoperative AND radiotherapy) OR (IORT OR IOERT OR IOEBRT))

Current Controlled Trials, International Standard Randomised Controlled Trial Number Register (ISRCTN):

((breast AND (cancer* OR tumor* OR tumour* OR carcinoma OR neoplasm))) AND ((intraoperative AND radiation AND therapy) OR (intraoperative AND radiotherapy) OR (IORT OR IOERT OR IOEBRT))

International Clinical Trials (WHO):

((breast AND (cancer* OR tumor* OR tumour* OR carcinoma OR neoplasm))) AND ((intraoperative AND radiation AND therapy) OR (intraoperative AND radiotherapy) OR (IORT OR IOERT OR IOEBRT))

European Union Clinical Trials Register:

breast AND intraoperative AND (radiotherapy OR radiation OR IORT OR IOERT OR IOEBRT) 



\section{Bibliografía}

1. World Health Organization. Estimated Cancer Incidence, Mortality and Prevalence Worldwide in 2018: International Agency for Research on Cancer [Internet]. GLOBOCAN 2018. [Última actualización 2018, fecha de consulta 2018/12/11]. Disponible en: http://gco.iarc.fr/today/fact-sheets-cancers.

2. Cantero Muñoz P, Atienza Merino G. Radioterapia intraoperatoria en el tratamiento del cáncer de mama. Red Española de Agencias de Evaluación de Tecnologías Sanitarias y Presataciones del SNS. Agencia de Evaluación de Tecnologías Sanitarias de Galicia. Informes de evaluación de tecnologías sanitarias. 2013.

3. Galceran J, Ameijide A, Carulla M, Mateos A, Quiros JR, Rojas D, et al. Cancer incidence in Spain, 2015. Clin Transl Oncol. 2017;19(7):799-825.

4. Instituto de Salud Carlos III. Mortalidad por cáncer y otras causas en España. Área de epidemiología Ambiental y Cáncer. Centro Nacional de Epidemiología. ISCIII. 2015.

5. Sant M, Chirlaque Lopez MD, Agresti R, Sanchez Perez MJ, Holleczek B, Bielska-Lasota M, et al. Survival of women with cancers of breast and genital organs in Europe 1999-2007: Results of the EUROCARE-5 study. Eur J Cancer. 2015;51(15):2191-205.

6. Picot J, Copley V, Colquitt JL, Kalita N, Hartwell D, Bryant J. The INTRABEAM(R) Photon Radiotherapy System for the adjuvant treatment of early breast cancer: a systematic review and economic evaluation. Health TechnolAssess. 2015;19(69):1-190.

7. National Cancer Institute. Breast Cancer Treatment (PDQ $\left.{ }^{\circledR}\right)$-Health Professional Version. [fecha de consulta 10/04/2019/]. Disponible en: https://www. cancer.gov/types/breast/hp/breast-treatment-pdq.

8. Rodríguez N, Murillo MT, González E, de la Fuente C, Moreno F. Irradiación parcial acelerada en cáncer de mama: revisión de las diferentes técnicas. Rev Senol Patol Mamar. 2014;27(1):34-42.

9. Sperk E, Astor D, Keller A, Welzel G, Gerhardt A, Tuschy B, et al. A cohort analysis to identify eligible patients for intraoperative radiotherapy (IORT) of early breast cancer. Radiat Oncol. 2014;9:154.

10. Vaidya JS, Wenz F, Bulsara M, Tobias JS, Joseph DJ, Keshtgar M, et al. Riskadapted targeted intraoperative radiotherapy versus whole-breast radiotherapy for breast cancer: 5-year results for local control and overall survival from the TARGIT-A randomised trial. Lancet. 2014;383(9917):603-13. 
11. Veronesi U, Orecchia R, Maisonneuve P, Viale G, Rotmensz N, Sangalli C, et al. Intraoperative radiotherapy versus external radiotherapy for early breast cancer (ELIOT): a randomised controlled equivalence trial. Lancet Oncol. 2013;14(13):1269-77.

12. Massa M, Meszaros P, Baldelli I, Bisso N, Franchelli S. Aesthetic evaluation in oncoplastic and conservative breast surgery: a comparative analysis. Plast Reconstr Surg Glob Open. 2015;3(3):e339.

13. Balshem H, Helfand M, Schunemann HJ, Oxman AD, Kunz R, Brozek J, et al. GRADE guidelines: 3. Rating the quality of evidence. J Clin Epidemiol. 2011;64(4):401-6.

14. Guyatt GH, Oxman AD, Vist G, Kunz R, Brozek J, Alonso-Coello P, et al. GRADE guidelines: 4. Rating the quality of evidence--study limitations (risk of bias). J Clin Epidemiol. 2011;64(4):407-15.

15. Guyatt GH, Oxman AD, Kunz R, Woodcock J, Brozek J, Helfand M, et al. GRADE guidelines: 7. Rating the quality of evidence--inconsistency. J Clin Epidemiol. 2011;64(12):1294-302.

16. Guyatt GH, Oxman AD, Kunz R, Woodcock J, Brozek J, Helfand M, et al. GRADE guidelines: 8. Rating the quality of evidence--indirectness. J Clin Epidemiol. 2011;64(12):1303-10.

17. Guyatt GH, Oxman AD, Kunz R, Brozek J, Alonso-Coello P, Rind D, et al. GRADE guidelines: 6. Rating the quality of evidence--imprecision. J Clin Epidemiol. 2011;64(12):1283-93.

18. Guyatt GH, Oxman AD, Montori V, Vist G, Kunz R, Brozek J, et al. GRADE guidelines: 5. Rating the quality of evidence--publication bias. J Clin Epidemiol. 2011;64(12):1277-82.

19. Guyatt GH, Oxman AD, Sultan S, Glasziou P, Akl EA, Alonso-Coello P, et al. GRADE guidelines: 9. Rating up the quality of evidence. J Clin Epidemiol. 2011;64(12):1311-6.

20. López de Argumedo M, Reviriego E, Andrio E, Rico R, Sobradillo N, Hurtado de Saracho I. Revisión externa y validación de instrumentos metodológicos para la Lectura Crítica y la síntesis de la evidencia. Madrid: Plan Nacional para el SNS del MSC. Servicio de Evaluación de Tecnologías Sanitarias del País Vasco (Osteba); 2006. Informes de Evaluación de Tecnologías Sanitarias: OSTEBA N² 2006/02.

21. Fletcher J. What is heterogeneity and is it important? BMJ. 2007;334(7584):94-6.

22. Ioannidis JP, Patsopoulos NA, Evangelou E. Uncertainty in heterogeneity estimates in meta-analyses. BMJ. 2007;335(7626):914-6.

23. Cracco S, Semprini G, Cattin F, Gregoraci G, Zeppieri M, Isola M, et al. Impact of intraoperative radiotherapy on cosmetic outcome and complications after oncoplastic breast surgery. Breast J. 2015;21(3):285-90. 
24. Ebner F, Schramm A, Bottke D, Friedl TW, Wiegel T, Fink V, et al. Comparison of seroma production in breast conserving surgery with or without intraoperative radiotherapy as tumour bed boost. Arch Gynecol Obstet. 2016;294(4):861-6.

25. Elsberger B, Romsauerova A, Vinnicombe S, Whelehan P, Brown DC, Dewar JA, et al. Comparison of mammographic findings after intraoperative radiotherapy or external beam whole breast radiotherapy. EurJ Surg Oncol. 2014;40(2):163-7.

26. Engel D, Schnitzer A, Brade J, Blank E, Wenz F, Suetterlin M, et al. Are mammographic changes in the tumor bed more pronounced after intraoperative radiotherapy for breast cancer? Subgroup analysis from a randomized trial (TARGIT-A). Breast J. 2013;19(1):92-5.

27. Epstein M, Silverstein M, Lin K, Kim B, Khan S, De Leon C, et al. Acute and Chronic Complications in Breast Cancer Patients Treated with Intraoperative Radiation Therapy. Ann Surg Oncol. 2016;23(10):3304-9.

28. Falco M, Masojc B, Rolla M, Czekala A, Pietruszewska J, Rubik-Leszczynska A, et al. Risk factors for seroma evacuation in breast cancer patients treated with intraoperative radiotherapy. RepPractOncol Radiother. 2016;21(3):225-31.

29. Fernandez Carrion M, Miralles Curto M, Piñar Sedeño B, Rosas Bermudez C, Rodriguez Ibarria N, Sosa Quesada Y, et al. Radioterapia intraoperatoria de la mama con Intrabeam ${ }^{\circledR}$ : experiencia inicial en nuestro centro. Rev Senol Patol Mamar. 2016;29(4):163-9.

30. Gunay S, Alan O, Yalcin O, Turkmen A, Dizdar N. Our intraoperative boost radiotherapy experience and applications. Ulus Cerrahi Derg. 2016;32(1):30-6.

31. Hanna SA, de Barros AC, de Andrade FE, Bevilacqua JL, Piato JR, Pelosi EL, et al. Intraoperative radiation therapy in early breast cancer using a linear accelerator outside of the operative suite: an "image-guided" approach. Int J Radiat Oncol Biol Phys. 2014;89(5):1015-23.

32. Osti MF, Carnevale A, Bracci S, Amanti C, Lombardi A, Maggi S, et al. Exclusive electron intraoperative radiotherapy in early-stage breast cancer: a monoinstitutional experience. Anticancer Res. 2013;33(3):1229-35.

33. Miglierini P, Key S, Dupré P, Le Fur E, Miranda O, Lucia A, et al. Brest experience in intraoperative radiotherapy for breast cancer. Transl Cancer Res. 2014;3(2):175-9.

34. Paredes R, Hernández G, Cossom A, González C, Hernández J, Rodríguez I. Radioterapia intraoperatoria (Intrabeam). Técnica de aplicación. Experiencia en la Unidad de Mastología Clínica Leopoldo Aguerrevere. Rev Venez Oncol. 2015;27(1):30-6.

35. Philippson C, Simon S, Vandekerkhove C, Hertens D, Veys I, Noterman D, et al. Early invasive cancer and partial intraoperative electron radiation therapy 
of the breast: experience of the jules bordet institute. Int J Breast Cancer. 2014;2014:627352.

36. Rocco N, Rispoli C, Iannone L, Testa S, ntonio Della CG, Compagna R, et al. Intraoperative radiation therapy with electrons in breast cancer conservative treatment: our experience. Int J Surg. 2014;12 Suppl 1:S75-S8.

37. Sawaki M, Kondo N, Horio A, Ushio A, Gondo N, Adachi E, et al. Feasibility of intraoperative radiation therapy for early breast cancer in Japan: a singlecenter pilot study and literature review. Breast Cancer. 2014;21(4):415-22.

38. Syed AMN, Chang H, Schwartzberg BS, Bremner AK, Lopez-Penalver C, Coomer $\mathrm{C}$, et al. One-year follow-up results of a multi-center trial of intraoperative radiation therapy using electronic brachytherapy at the time of breast conservation surgery for early stage breast cancer. Cancer Research. 2016;76(4).

39. Vinh-Hung V, Nepote V, Rozenholc A, Vees H, Monnier S, CastiglioneGertsch M, et al. First year experience with IORT for breast cancer at the Geneva University Hospitals. Transl Cancer Res. 2014;3(1):65-73.

40. Valente SA, Tendulkar RD, Cherian S, O'Rourke C, Greif JM, Bailey L, et al. TARGIT-R (Retrospective): North American Experience with Intraoperative Radiation Using Low-Kilovoltage X-Rays for Breast Cancer. Ann Surg Oncol. 2016;23(9):2809-15.

41. Zur M, Shai A, Leviov M, Bitterman A, Shiloni E, Ben YR, et al. Short-term complications of intra-operative radiotherapy for early breast cancer. J Surg Oncol. 2016;113(4):370-3.

42. Kawamura M, Itoh Y, Sawaki M, Kikumori T, Tsunoda N, Kamomae T, et al. A phase I/II trial of intraoperative breast radiotherapy in an Asian population: 5-year results of local control and cosmetic outcome. Radiat Oncol. 2015;10:150.

43. Saibene T, Michieletto S, Evangelista L, Bianchi A, Orvieto E, Lora O, et al. Intraoperative radiotherapy during breast cancer surgery: Acute and chronic cardiac safety tested by an ultra-sensitive troponin and N-terminal pro-B-type natriuretic peptide. European Journal of Oncology. 2014;19(3):159-65.

44. Grantzau T, Overgaard J. Risk of second non-breast cancer after radiotherapy for breast cancer: a systematic review and meta-analysis of 762,468 patients. Radiother Oncol. 2015;114(1):56-65.

45. Mallick S, Giridhar P, Prasad Venkatesulu B. In regard to "Risk of second non-breast cancer after radiotherapy for breast cancer: A systematic review and meta-analysis of 762,468 patients”. Radiother Oncol. 2015;115(3):431.

46. Trifiletti DM, Showalter TN, Libby B, Brenin DR, Schroen AT, Reardon KA, et al. Intraoperative breast radiation therapy with image guidance: Findings from CT images obtained in a prospective trial of intraoperative high-doserate brachytherapy with CT on rails. Brachytherapy. 2015;14(6):919-24. 
47. Tuschy B, Berlit S, Nasterlack C, Tome K, Blank E, Wenz F, et al. Intraoperative radiotherapy of early breast cancer using low-kilovoltage $\mathrm{x}$-rays-reasons for omission of planned intraoperative irradiation. Breast J. 2013;19(3):325-8.

48. Alvarado MD, Conolly J, Park C, Sakata T, Mohan AJ, Harrison BL, et al. Patient preferences regarding intraoperative versus external beam radiotherapy following breast-conserving surgery. Breast Cancer Res Treat. 2014;143(1):135-40.

49. Corica T, Joseph D, Saunders C, Bulsara M, Nowak AK. Intraoperative radiotherapy for early breast cancer: do health professionals choose convenience or risk? Radiat Oncol. 2014;9:33.

50. Corica T, Nowak AK, Saunders CM, Bulsara M, Taylor M, Vaidya JS, et al. Cosmesis and Breast-Related Quality of Life Outcomes After Intraoperative Radiation Therapy for Early Breast Cancer: A Substudy of the TARGIT-A Trial. Int J Radiat Oncol Biol Phys. 2016;96(1):55-64.

51. Grobmyer SR, Lightsey JL, Bryant CM, Shaw C, Yeung A, Bhandare N, et al. Low-kilovoltage, single-dose intraoperative radiation therapy for breast cancer: results and impact on a multidisciplinary breast cancer program. J Am CollSurg. 2013;216(4):617-23.

52. Lemanski C, Azria D, Gourgou-Bourgade S, Ailleres N, Pastant A, Rouanet $\mathrm{P}$, et al. Electrons for intraoperative radiotherapy in selected breast-cancer patients: late results of the Montpellier phase II trial. Radiat Oncol. 2013;8:191.

53. Zhou SF, Shi WF, Meng D, Sun CL, Jin JR, Zhao YT. Interoperative radiotherapy of seventy-two cases of early breast cancer patients during breast-conserving surgery. Asian PacJ Cancer Prev. 2012;13(4):1131-5.

54. Mobit PN, Rajaguru P, Brewer M, Baird M, Packianathan S, Yang CC. Radiation safety consideration during intraoperative radiation therapy. Radiat Prot Dosimetry. 2015;164(3):376-82.

55. Shah C, Badiyan S, Khwaja S, Shah H, Chitalia A, Nanavati A, et al. Evaluating radiotherapy options in breast cancer: does intraoperative radiotherapy represent the most cost-efficacious option? Clin Breast Cancer. 2014;14(2):141-6.

56. Alvarado MD, Mohan AJ, Esserman LJ, Park CC, Harrison BL, Howe RJ, et al. Cost-effectiveness analysis of intraoperative radiation therapy for earlystage breast cancer. Ann Surg Oncol. 2013;20(9):2873-80.

57. Zhang L, Zhou Z, Mei X, Yang Z, Ma J, Chen X, et al. Intraoperative Radiotherapy Versus Whole-Breast External Beam Radiotherapy in EarlyStage Breast Cancer: A Systematic Review and Meta-Analysis. Medicine (Baltimore). 2015;94(27):e1143.

58. Beal K, McCormick B, Zelefsky MJ, Borgen P, Fey J, Goldberg J, et al. Singlefraction intraoperative radiotherapy for breast cancer: early cosmetic results. Int J Radiat Oncol Biol Phys. 2007;69(1):19-24. 
59. Dubois JB, Hay M, Gely S, Saint-Aubert B, Rouanet P, Pujol H. IORT in breast carcinomas. Front Radiat Ther Oncol. 1997;31:131-7.

60. España. Real Decreto 783/2001, de 6 de julio, por el que se aprueba el Reglamento sobre protección sanitaria contra radiaciones ionizantes. Boletín Oficial del Estado, 26 de julio de 2001, núm: 178, pp. 27284-27393.

61. Vaidya JS, Joseph DJ, Tobias JS, Bulsara M, Wenz F, Saunders C, et al. Targeted intraoperative radiotherapy versus whole breast radiotherapy for breast cancer (TARGIT-A trial): an international, prospective, randomised, noninferiority phase 3 trial. Lancet. 2010;376(9735):91-102.

62. Esposito E, Anninga B, Harris S, Capasso I, D'Aiuto M, Rinaldo M, et al. Intraoperative radiotherapy in early breast cancer. Br J Surg. 2015;102(6):599610.

63. Silverstein MJ, Fastner G, Maluta S, Reitsamer R, Goer DA, Vicini F, et al. Intraoperative radiation therapy: a critical analysis of the ELIOT and TARGIT trials. Part 1--ELIOT. Ann Surg Oncol. 2014;21(12):3787-92.

64. Vaidya JS, Wenz F, Bulsara M, Tobias JS, Joseph DJ, Saunders C, et al. An international randomised controlled trial to compare TARGeted Intraoperative radioTherapy (TARGIT) with conventional postoperative radiotherapy after breast-conserving surgery for women with early-stage breast cancer (the TARGIT-A trial). Health Technol Assess. 2016;20(73):1-188.

65. Haviland JS, Bliss JM, Bentzen SM, Cuzick J. In Regard to Vaidya et al. Int J Radiat Oncol Biol Phys. 2015;92(5):954-5.

66. Hepel J, Wazer DE. A flawed study should not define a new standard of care. Int J Radiat Oncol Biol Phys. 2015;91(2):255-7.

67. Cuzick J. Radiotherapy for breast cancer, the TARGIT-A trial. Lancet. 2014;383(9930):1716.

68. Abbott AM, Valente SA, Loftus L, Tendulkar RD, Greif JM, Bethke KP, et al. A multi-institutional analysis of intraoperative radiotherapy for early breast cancer: Does age matter? Am J Surg. 2017;214(4):629-33.

69. Shah C, Badiyan S, Berry S, Khan AJ, Goyal S, Schulte K, et al. Cardiac dose sparing and avoidance techniques in breast cancer radiotherapy. Radiother Oncol. 2014;112(1):9-16.

70. Abbott AM, Dossett LA, Loftus L, Sun W, Fulp W, Sokol GH, et al. Intraoperative radiotherapy for early breast cancer and age: clinical characteristics and outcomes. Am J Surg. 2015;210(4):624-8.

71. Almeida N, Dendukuri N. Using Intrabeam ${ }^{\circledR}$ for early-stage breast cancer: a health technology assessment. Update of TAU report \#63: single-dose intraoperative radiotherapy. Montreal (Canada): Technology Assessment Unit (TAU) of the McGill University Health Centre (MUHC); 2015 June 9. Report $\mathrm{n}^{\circ} 76.59 \mathrm{p}$. 
72. Arsenali B, de Jong HW, Viergever MA, Dickerscheid DB, Beijst C, Gilhuijs KG. Dual-head gamma camera system for intraoperative localization of radioactive seeds. Phys Med Biol. 2015;60(19):7655-70.

73. Baghani HR, Aghamiri SM, Mahdavi SR, Robatjazi M, Zadeh AR, Akbari ME, et al. Dosimetric evaluation of Gafchromic EBT2 film for breast intraoperative electron radiotherapy verification. Phys Med. 2015;31(1):37-42.

74. Barros AC, Hanna SA, Carvalho HA, Martella E, Andrade FE, Piato JR, et al. Intraoperative full-dose of partial breast irradiation with electrons delivered by standard linear accelerators for early breast cancer. Int J Breast Cancer. 2014;2014:568136.

75. Barry M, Ho A, Morrow M. The evolving role of partial breast irradiation in early-stage breast cancer. Ann Surg Oncol. 2013;20(8):2534-40.

76. Bouzid D, Bert J, Dupre PF, Benhalouche S, Pradier O, Boussion N, et al. Monte-Carlo dosimetry for intraoperative radiotherapy using a low energy x-ray source. Acta Oncol. 2015;54(10):1788-95.

77. Bromberg SE, Hanriot RM, Nazario AC. Intraoperative radiotherapy as a protocol for the treatment of initial breast cancer. Einstein (Sao Paulo). 2013;11(4):439-45.

78. Budrukkar A, Gurram L, Upreti RR, Munshi A, Jalali R, Badwe R, et al. Clinical outcomes of prospectively treated 140 women with early stage breast cancer using accelerated partial breast irradiation with 3 dimensional computerized tomography based brachytherapy. Radiother Oncol. 2015;115 (3):349-54.

79. Calvo F, Sole C, Herranz R, Lopez-Bote M, Pascau J, Santos A, et al. Intraoperative radiotherapy with electrons: fundamentals, results, and innovation. ecancermedicalscience. 2013;7:339.

80. Cedolini C, Bertozzi S, Seriau L, Londero AP, Concina S, Moretti E, et al. Feasibility of concervative breast surgery and intraoperative radiation therapy for early breast cancer: a single-center, open, non-randomized, prospective pilot study. Oncol Rep. 2014;31(4):1539-46.

81. Coombs NJ, Coombs JM, Vaidya UJ, Singer J, Bulsara M, Tobias JS, et al. Environmental and social benefits of the targeted intraoperative radiotherapy for breast cancer: data from UK TARGIT-A trial centres and two UK NHS hospitals offering TARGIT IORT. BMJ Open. 2016;6(5):e010703.

82. Cox JA, Swanson TA. Current modalities of accelerated partial breast irradiation. NatRev Clin Oncol. 2013;10(6):344-56.

83. Eaton DJ, Earner B, Faulkner P, Dancer N. A national dosimetry audit of intraoperative radiotherapy. Br J Radiol. 2013;86(1032):20130447.

84. Eaton DJ. Electronic brachytherapy--current status and future directions. $\mathrm{Br}$ J Radiol. 2015;88(1049):20150002. 
85. Esposito E, Compagna R, Rinaldo M, Falivene S, Ravo V, Amato B, et al. Intraoperative radiotherapy in elderly patients with breast cancer: Is there a clinical applicability? Review of the current evidence. Int J Surg. 2016;33 Suppl 1:S88-S91.

86. Esserman LJ, Alvarado MD, Howe RJ, Mohan AJ, Harrison B, Park C, et al. Application of a decision analytic framework for adoption of clinical trial results: are the data regarding TARGIT-A IORT ready for prime time? Breast Cancer Res Treat. 2014;144(2):371-8.

87. Fastner G, Sedlmayer F, Merz F, Deutschmann H, Reitsamer R, Menzel C, et al. IORT with electrons as boost strategy during breast conserving therapy in limited stage breast cancer: long term results of an ISIORT pooled analysis. Radiother Oncol. 2013;108(2):279-86.

88. Fastner G, Reitsamer R, Ziegler I, Zehentmayr F, Fussl C, Kopp P, et al. IOERT as anticipated tumor bed boost during breast-conserving surgery after neoadjuvant chemotherapy in locally advanced breast cancer--results of a case series after 5-year follow-up. Int J Cancer. 2015;136(5):1193-201.

89. Fastner G, Hauser-Kronberger C, Moder A, Reitsamer R, Zehentmayr F, Kopp P, et al. Survival and local control rates of triple-negative breast cancer patients treated with boost-IOERT during breast-conserving surgery. StrahlentherOnkol. 2016;192(1):1-7.

90. Goble RN, Drukteinis JS, Lee MC, Khakpour N, Kiluk JV, Laronga C. Early experience with ultrasound features after intrabeam intraoperative radiation for early stage breast cancer. J Surg Oncol. 2014;109(8):751-5.

91. Goggin LM, Descovich M, McGuinness C, Shiao S, Pouliot J, Park C. Dosimetric Comparison Between 3-Dimensional Conformal and Robotic SBRT Treatment Plans for Accelerated Partial Breast Radiotherapy. TechnolCancer Res Treat. 2016;15(3):437-45.

92. Hanna GG, Kirby AM. Intraoperative radiotherapy in early stage breast cancer: potential indications and evidence to date. Br J Radiol. 2015;88 (1049):20140686.

93. Hickey BE, Lehman M, Francis DP, See AM. Partial breast irradiation for early breast cancer. Cochrane Database Syst Rev. 2016;7:CD007077.

94. Hickey BE, James ML, Lehman M, Hider PN, Jeffery M, Francis DP, et al. Fraction size in radiation therapy for breast conservation in early breast cancer. Cochrane Database Syst Rev. 2016;7:CD003860.

95. Horst KC, Ikeda DM, Fero KE, Daniel BL, Goffinet DR, Dirbas FM. Breast magnetic resonance imaging alters patient selection for accelerated partial breast irradiation. Am J Clin Oncol. 2014;37(3):248-54.

96. Cantero Muñoz P, Eraso Urién M, Ruano Raviña A. Radioterapia intraoperatoria en cáncer de mama y cáncer colorrectal. Santiago de Compostela: 
Consellería de Sanidade. Axencia de Avaliación de Tecnoloxías Sanitarias de Galicia, avalia-t; 2009. Serie Avaliación de Tecnoloxías. Informe de evaluación; IA2010/01.

97. Jalaguier-Coudray A, Cohen M, Thomassin-Piana J, Houvenaeghel G, Villard-Mahjoub R, Tallet A, et al. Calcifications and tungsten deposits after breast-conserving surgery and intraoperative radiotherapy for breast cancer. EurJ Radiol. 2015;84(12):2521-5.

98. Jones R, Libby B, Showalter SL, Brenin DR, Wilson DD, Schroen A, et al. Dosimetric comparison of (192)Ir high-dose-rate brachytherapy vs. $50 \mathrm{kV}$ x-rays as techniques for breast intraoperative radiation therapy: conceptual development of image-guided intraoperative brachytherapy using a multilumen balloon applicator and in-room CT imaging. Brachytherapy. 2014;13(5):502-7.

99. Kalakota K, Small W, Jr. Intraoperative radiation therapy techniques and options for breast cancer. Expert Rev Med Devices. 2014;11(3):265-73.

100. Khan AJ, Vicini FA, Brown S, Haffty BG, Kearney T, Dale R, et al. Dosimetric feasibility and acute toxicity in a prospective trial of ultrashort-course accelerated partial breast irradiation (APBI) using a multi-lumen balloon brachytherapy device. Ann Surg Oncol. 2013;20(4):1295-301.

101. Khan AJ, Ahlawat S, Goyal S. Novel and Highly Compressed Schedules for the Treatment of Breast Cancer. Semin Radiat Oncol. 2016;26(1):45-50.

102. Krengli M, Sedlmayer F, Calvo FA, Sperk E, Pisani C, Sole CV, et al. ISIORT pooled analysis 2013 update: clinical and technical characteristics of intraoperative radiotherapy. Transl Cancer Res. 2014;3(1):48-58.

103. Kunkler IH, Audisio R, Belkacemi Y, Betz M, Gore E, Hoffe S, et al. Review of current best practice and priorities for research in radiation oncology for elderly patients with cancer: the International Society of Geriatric Oncology (SIOG) task force. Ann Oncol. 2014;25(11):2134-46.

104. Kuzba Kryszak T, Biedka M, Ziotkowski S, Makarewicz A. Intraoperative radiotherapy using in breast cancer of women. Oncol Radiotherapy. 2015;1:22-30.

105. Lehman M, Hickey BE, Francis DP, See AM. Partial breast irradiation for early breast cancer. Cochrane Database Syst Rev. 2014(6):CD007077.

106. Lemanski C. Radiotherapy: new tools for modulation and personalized treatments. Oncologie. 2016;18:128-33.

107. Leonardi MC, Maisonneuve P, Mastropasqua MG, Morra A, Lazzari R, Dell'acqua V, et al. Accelerated partial breast irradiation with intraoperative electrons: using GEC-ESTRO recommendations as guidance for patient selection. Radiother Oncol. 2013;106(1):21-7.

108. Liu Q, Schneider F, Ma L, Wenz F, Herskind C. Relative Biologic Effectiveness (RBE) of $50 \mathrm{kV}$ X-rays measured in a phantom for intraoperative tumorbed irradiation. Int J Radiat Oncol Biol Phys. 2013;85(4):1127-33. 
109. Livi L, Meattini I, Marrazzo L, Simontacchi G, Pallotta S, Saieva C, et al. Accelerated partial breast irradiation using intensity-modulated radiotherapy versus whole breast irradiation: 5-year survival analysis of a phase 3 randomised controlled trial. EurJ Cancer. 2015;51(4):451-63.

110. Lopez-Tarjuelo J, Morillo-Macias V, Bouche-Babiloni A, Ferrer-Albiach C, Santos-Serra A. Defining Action Levels for In Vivo Dosimetry in Intraoperative Electron Radiotherapy. TechnolCancer Res Treat. 2016;15(3):453-9.

111. Lopez-Tarjuelo J, Morillo-Macias V, Bouche-Babiloni A, Boldo-Roda E, Lozoya-Albacar R, Ferrer-Albiach C. Implementation of an intraoperative electron radiotherapy in vivo dosimetry program. Radiat Oncol. 2016;11:41.

112. Malter W, Kirn V, Richters L, Fridrich C, Markiefka B, Bongartz R, et al. Intraoperative Boost Radiotherapy during Targeted Oncoplastic Breast Surgery: Overview and Single Center Experiences. Int J Breast Cancer. 2014;2014:637898.

113. Maluta S, Dall'oglio S, Goer DA, Marciai N. Intraoperative Electron Radiotherapy (IOERT) as an Alternative to Standard Whole Breast Irradiation: Only for Low-Risk Subgroups? Breast Care (Basel). 2014;9(2):102-6.

114. Marta GN, Macedo CR, Carvalho HA, Hanna SA, da Silva JL, Riera R. Accelerated partial irradiation for breast cancer: systematic review and metaanalysis of 8653 women in eight randomized trials. Radiother Oncol. 2015;114(1):42-9.

115. Massarut S, Belleti B, Segatto I, Piccoli E, Baldassarre G. Wound response after intraoperative radiotherapy. Transl Cancer Res. 2015;4(2):161-72.

116. Meattini I, Saieva C, Marrazzo L, Di BL, Pallotta S, Mangoni M, et al. Accelerated partial breast irradiation using intensity-modulated radiotherapy technique compared to whole breast irradiation for patients aged 70 years or older: subgroup analysis from a randomized phase 3 trial. Breast Cancer Res Treat. 2015;153(3):539-47.

117. Merdad AA, Bahadur YA, Fawzy EE, Hassouna AH, Eltaher MM, Alghaithy ZK, et al. Phase II study on the use of intraoperative radiotherapy in early breast cancer. Saudi Med J. 2013;34(11):1133-8.

118. Murawa P, Murawa D, Adamczyk B, Polom K. Breast cancer: Actual methods of treatment and future trends. RepPractOncol Radiother. 2014;19(3):165-72.

119. Orecchia R, Leonardi M, Maisonneuve P, Morra A, Lazzari R, Cattani F, et al. Intraoparative radiotherapy with electrons (ELIOT) for early breast cancer: the European Institute of Oncology experience. Transl Cancer Res. 2014;3(1):59-64.

120. Pan L, Zheng W, Ye X, Chen L, Ke Y, Wan M, et al. A novel approach of INTRABEAM intraoperative radiotherapy for nipple-sparing mastectomy with breast reconstruction. Clin Breast Cancer. 2014;14(6):435-41. 
121. Piroth MD, Eble MJ. Intraoperative radiotherapy with electrons. Transl Cancer Res. 2014;3(2):167-74.

122. Riet FG, Rivera S. AERIO news in brief - Intraoperative radiotherapy versus external radiotherapy for early breast cancer (ELIOT): A randomised controlled equivalence trial. Oncologie. 2014;16(4):207-8.

123. Rivera R, Banks A, Casillas-Lopez A, Rashtian A, Lewinsky B, Sheth P, et al. Targeted Intraoperative Radiotherapy for the Management of Ductal Carcinoma In Situ of the Breast. Breast J. 2016;22(1):63-74.

124. Rodriguez-Spiteri SN, Martinez RF, Olartecoechea LB, Arredondo CJ, Cambeiro VM, Pina Insausti LJ, et al. [Accelerated partial breast irradiation with multicatheters during breast conserving surgery for cancer]. CirEsp. 2013;91(8):490-5.

125. Schaverien MV, Stallard S, Dodwell D, Doughty JC. Use of boost radiotherapy in oncoplastic breast-conserving surgery - a systematic review. EurJ Surg Oncol. 2013;39(11):1179-85.

126. Sedlmayer F, Reitsamer R, Fussl C, Ziegler I, Zehentmayr F, Deutschmann $\mathrm{H}$, et al. Boost IORT in Breast Cancer: Body of Evidence. Int J Breast Cancer. 2014;2014:472516.

127. Severgnini M, de DM, Bortul M, Vidali C, Beorchia A. In vivo dosimetry and shielding disk alignment verification by EBT3 GAFCHROMIC film in breast IOERT treatment. J Appl Clin Med Phys. 2015;16(1):5065.

128. Shokrani P, Soltani M. Beam characteristics and leakage assessment of an inhouse intra-operative electron applicator system. Int $\mathrm{J}$ Radiat Res. 2013;11(3):175-81.

129. Silverstein MJ, Fastner G, Maluta S, Reitsamer R, Goer DA, Vicini F, et al. Intraoperative radiation therapy: a critical analysis of the ELIOT and TARGIT trials. Part 2--TARGIT. Ann Surg Oncol. 2014;21(12):3793-9.

130. Spano JP, Azria D, Goncalves A. Patients' satisfaction in early breast cancer treatment: Change in treatment over time and impact of HER2-targeted therapy. Crit Rev Oncol Hematol. 2015;94(3):270-8.

131. Strnad V. Multicatheter brachytherapy is the best for APBI. Radiotherapy and Oncology. 2016;119:S141.

132. Tejera AA, Vega V, Romero R, Pinar B, Rodríguez N, Vallvé M, et al. Uso de la radioterapia intraoperatoria (RIO) en el cáncer de mama. Técnica quirúrgica, ventajas y desventajas. Cir Esp. 2015;93(Espec Congr):770.

133. Thompson AM, Yarnold J. Intraoperative Radiotherapy: Is it Ready for Prime Time? Current Breast Cancer Reports. 2015;7(1):15-21.

134. Tian S, Paster LF, Kim S, Kirstein L, Haffty BG, Ferro A, et al. Comparison of Mammographic Changes Across Three Different Fractionation 
Schedules for Early-Stage Breast Cancer. IntJ RadiatOncol BiolPhys. 2016;95(2):597-604.

135. Trifiletti DM, Jones R, Showalter SL, Libby BB, Brenin DR, Schroen A, et al. Techniques for intraoperative radiation therapy for early-stage breast carcinoma. Future Oncol. 2015;11(7):1047-58.

136. Tuschy B, Berlit S, Romero S, Sperk E, Wenz F, Kehl S, et al. Influence of age on short-term complications after intraoperative radiotherapy in women after breast-conserving surgery. Anticancer Res. 2013;33(9):3995-9.

137. Tuschy B, Berlit S, Romero S, Sperk E, Wenz F, Kehl S, et al. Clinical aspects of intraoperative radiotherapy in early breast cancer: short-term complications after IORT in women treated with low energy x-rays. Radiat Oncol. 2013;8:95.

138. Valdivieso-Casique M, Rodríguez R, Rodríguez-Bescós S, Lardíes D, Guerra $\mathrm{P}$, Ledesma MJ, et al. RADIANCE - A planing software for intra-operative radiation therapy. Transl Cancer Res. 2015;4(2):196-209.

139. Vanderwalde NA, Jones EL, Kimple RJ, Moore DT, Klauber-Demore N, Sartor CI, et al. Phase 2 study of pre-excision single-dose intraoperative radiation therapy for early-stage breast cancers: six-year update with application of the ASTRO accelerated partial breast irradiation consensus statement criteria. Cancer. 2013;119(9):1736-43.

140. Vanoni V, Bou Selman S, Mussari S, Menegotti L, Rosa M, Tomio L. External beam radiation therapy versus intraoperative radiation therapy for breastconserving therapy: A large single-institution matched-pair evaluation. International Journal of Radiation Oncology Biology Physics. 2014;90(1):S261.

141. Veronesi P, De LF, Loschi P, Rietjens M, Veronesi U. Current Trends in the Oncologic and Surgical Managements of Breast Cancer in Women with Implants: Incidence, Diagnosis, and Treatment. Aesthetic Plast Surg. 2016;40(2):256-65.

142. Wang X, Liu J, Wang W, Feng Q, Wang X. Clinical analysis of intraoperative radiotherapy during breast-conserving surgery of early breast cancer in the Chinese Han population. Oncotarget. 2015;6(40):43120-6.

143. Wang L, Guyatt GH, Kennedy SA, Romerosa B, Kwon HY, Kaushal A, et al. Predictors of persistent pain after breast cancer surgery: a systematic review and meta-analysis of observational studies. CMAJ. 2016;188(14):E352-E61.

144. Warenczak-Florczak Z, Roszak A, Bratos K, Milecki P, Karczewska-Dzionk A, Wlodarczyk H. Intraoperative radiation therapy as part of breast conserving therapy of early breast cancer-Results of one-year follow-up. RepPractOncol Radiother. 2013;18(2):107-11.

145. Welzel G, Boch A, Sperk E, Hofmann F, Kraus-Tiefenbacher U, Gerhardt A, et al. Radiation-related quality of life parameters after targeted intraoperative 
radiotherapy versus whole breast radiotherapy in patients with breast cancer: results from the randomized phase III trial TARGIT-A. Radiat Oncol. 2013;8:9.

146. Wong WW, Pockaj BA, Vora SA, Halyard MY, Gray RJ, Schild SE. Six-year outcome of a prospective study evaluating tumor bed boost with intra-operative electron irradiation followed by whole-breast irradiation for early-stage breast cancer. Breast J. 2014;20(2):125-30.

147. Woolf DK, Williams NR, Bakshi R, Madani SY, Eaton DJ, Fawcitt S, et al. Biological dosimetry for breast cancer radiotherapy: a comparison of external beam and intraoperative radiotherapy. Springerplus. 2014;3:329.

148. Yu W, Lin Z, Ju ZJ, Li XR, Zhang YJ, Kong QL, et al. Intraoperative radiation therapy delivered prior to lumpectomy for early-stage breast cancer: a single institution study. Am J Cancer Res. 2015;5(7):2249-57.

149. Zioueche-Mottet A, Houvenaeghel G, Classe JM, Garbay JR, Giard S, Charitansky H, et al. Eligibility criteria for intraoperative radiotherapy for breast cancer: study employing 12,025 patients treated in two cohorts. BMC Cancer. 2014;14:868. 
